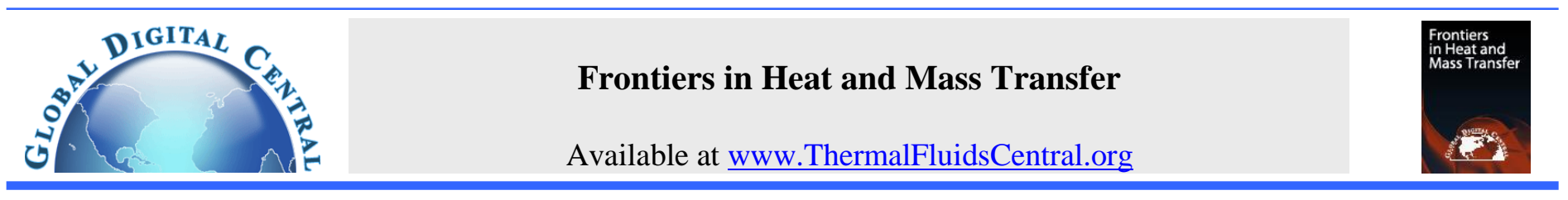

\title{
TURBINE BLADE LEADING EDGE IMPINGEMENT COOLING FROM NORMAL OR TANGENTIAL JETS WITH CROSSFLOW EFFECT
}

\author{
Nian Wang, Mingjie Zhang, Sulaiman Alsaleem, Lesley M. Wright, Je-Chin Han* \\ Turbine Heat Transfer Laboratory, Department of Mechanical Engineering, Texas A\&M University, College Station, Texas, 77843, USA
}

\begin{abstract}
This study investigates turbine blade, leading edge cooling from normal or tangential impinging jets. These jets impinging on a semi-cylindrical, inner surface are constrained to discharge in a single direction. The downstream jets are affected by the crossflow originating from the upstream jets. To understand the thermal flow physics, numerical simulations are performed using the realizable k- $\varepsilon$ turbulence model. Both the experimental and numerical results show crossflow is more detrimental to normal impinging jets than the tangential jets. Furthermore, with a significant temperature drop across the jet plate, designers must correctly interpret jet impingement results.
\end{abstract}

Keywords: Convective Heat Transfer; Turbine Cooling; Heat Transfer Enhancement

\section{INTRODUCTION}

Gas turbines are widely used in aircraft engines and the power industry. Higher engine thermal efficiency is directly related to a higher turbine, rotor inlet temperature (RIT). Currently, the RIT is around $1700^{\circ} \mathrm{C}$, which is far beyond the thermal yielding temperature $\left(1200^{\circ} \mathrm{C}\right)$ of the blade material. Researchers are continuously exploring opportunities to achieve even higher RITs up to $2000^{\circ} \mathrm{C}$ (Han, 2018). By increasing the firing temperature by $55 \mathrm{~K}$, the work output rises by approximately $10 \%$ and the thermal efficiency increases $1-1.5 \%$ (Boyce, 2001). To ensure safe and long-term engine operation, both a thermal barrier coating (TBC) and effective cooling techniques need to be incorporated. The current turbine blade cooling mechanisms are broadly divided into internal cooling and external cooling (film cooling). This paper focuses on internal impingement cooling.

\subsection{Jet Impingement Cooling}

Jet impingement is a mainstay for internal turbine cooling. With jet impingement, a pressurized chamber is separated from the target surface by a jet plate. The jet plate may contain either an array or matrix of discrete holes used to create a like pattern of jets to impinge on the target surface. Jet impingement is often utilized due to the potential to aggressively cool the target surface; however, this heat transfer enhancement comes at the expense of a relatively high pressure drop across the jet plate. Many publications and articles about jet impingement heat transfer for turbine airfoils are reviewed and documented (Han and Goldstein, 2001; Weigand and Spring, 2011; Han et al., 2012; Wright and Han, 2013; Amano and Sundén, 2014).

\subsection{Jet Impingement Heat Transfer Correlations}

Numerous studies that focus on impingement heat transfer have been reported over the past several decades. Heat transfer correlations have been developed to predict target surface heat transfer for many impingement configurations. Chupp et al. (1969) first developed an area-averaged heat transfer correlation for normal jet impingement on a concave surface. Kercher et al. (1970) presented average heat transfer correlations of a normal jet impinging on a flat plate, with the jet Reynolds number varying from 300 to 30,000. Correlations for an impingement array on a flat surface were developed by Metzger et al. (1979) and Florschuetz et al. (1980, 1981), and these correlations are widely used in the vane design process.

\subsection{Flow and Geometry Effects}

Jet Reynolds number, jet hole geometry (jet-to-jet spacing, jet-to-target surface spacing), jet hole shape (circular, racetrack, and slot), jet arrangement (in-lined and staggered), jet angle (straight and inclined) and jet hole location (normal and tangential) all effect target surface heat transfer. The available correlations (Chupp et al., 1969; Kercher and Tabakoff, 1970; Metzger et al., 1979; Florschuetz et al., 1980; Florschuetz et al., 1981) suggest that by increasing the jet Reynolds number, the heat transfer is enhanced. Kercher and Tabakoff (1970) conducted experiments to investigate the average surface heat transfer coefficient under a square array of circular air jets. They found that the jet Reynolds number and jet-to-jet spacing are important parameters influencing the heat transfer. Attalla (2005) found that the jet-to-target surface spacing, z/d, has a negligible effect on the heat transfer when $2 \leqslant \mathrm{z} / \mathrm{d} \leqslant 5$ for multiple jets. Taslim et al. (2001b) and Jordan et al. (2012, 2013, 2016) reported that racetrack shaped jet holes provided higher heat transfer coefficients than the round jet holes at the same flow condition. Van Treuren et al. (1996) compared the local and average heat transfer coefficients between inline and staggered impinging arrays. They concluded the average Nusselt number is slightly higher for the staggered case at relatively low Reynolds numbers. Xing et al. (2010) experimentally and numerically investigated the heat transfer of inline and staggered arrays of impinging jets. The local jet temperatures were measured to account for an exact evaluation of the heat transfer coefficient. Huang et al. (1998) estimated the heat transfer from an inclined jet $\left( \pm 45^{\circ}\right)$ impinging on a flat surface. The results show that the inclined jets were not as good as orthogonal jets. The optimized inclined racetrack holes were experimentally investigated by Carcasci et al. (2014). Liu et al. (2011) numerically studied the jet nozzle position effect and claimed that the average Nusselt number increases with the decrease of the spacing. Recently, Wang et al. (2018) investigated leading edge 
cooling with one row of normal or tangential impinging jets. The results showed that the area-averaged heat transfer coefficient produced by normal jets and tangential jets are comparable, while the local heat transfer distributions are entirely different. Biegger et al. (2018) considered tangential jets in a round swirl tube. High heat transfer was observed at the jet inlet with a decrease in the flow direction toward the next jet. From the surface and flow measurements, it was noted the increased turbulence in the vicinity of the jet enhances the heat transfer on the concave surface.

\subsection{Target Surface Effects}

The target surface effects on the impingement heat transfer have been researched as well. Gau and Chung (1991) reported that the local Nusselt number increases with increasing surface curvature. In recent years, to further enhance the heat transfer, the target surface can be artificially roughened with various turbulators such as ribs, dimples, pins, etc. By generating complex secondary flow, the target surface heat transfer can be enhanced. Azad et al. (2000) experimentally investigated the jet impinging on a pinned/dimpled surface. From their observation, a pinned surface can provide higher or lower heat transfer compared to a smooth surface, depending on the cross-flow direction. Kanokjaruvijit and Martinez-Botas (2005) claimed that the hemispherical dimple and shallower dimple are better than the cusped elliptical dimple and deeper dimple. Taslim et al. (2003) suggested that the rib-roughed surface yielded the highest heat transfer due to the area increase of the target surface. Mhetras et al. (2013) investigated the surfaces roughened with riblets, hemispherical dimples, and short pins. The Reynolds numbers were high ranging from 50,000 to 450,000. The short pinned surface provided the highest Nusselt number. Parbat et al. (2016) recently proposed three new surface futures: airfoil shaped dimples on a target surface, chevron elements, extending from the surface, and $45^{\circ}$ wedges mounted on a jet plate. Their results showed the airfoil shaped dimpled surface gave the best heat transfer enhancement. Buzzard et al. (2016a, 2016b) also systematically investigated the effect of target surface roughness on jet impingement heat transfer with $\mathrm{Re}=900,1,500,5,000$, and 11,000. Their results demonstrated the remarkable ability of roughness to enhance heat transfer.

\subsection{Crossflow Effect}

Crossflow effects should also be considered in the impingement cooling passage. In general, the presence of cross-flow reduces the heat transfer performance due to jet deflection arising by the upstream spent air. AlSanea (1992) numerically studied an impinging laminar slot-jet and claimed that the crossflow could degrade the nominal heat-transfer rate by as much as $60 \%$. Huang et al. (1998) reported that the direction of crossflow significantly altered the flow structure and the surface heat transfer distribution. Flow exits on both sides produced the highest Nusselt number on the surface due to the weakened crossflow effect. Kanokjaruvijit and Martinez-Botas (2008) investigated three different crossflow schemes. With Reynolds numbers ranging from 5,000 to 15,000 and jet-to-target surface spacing varying from 1 to 12 , they showed the minimum crossflow scheme provided the highest average heat transfer. Taslim et al. $(2005,2009)$ numerically and experimentally studied the jet impingement on an airfoil leading edge region and reported that crossflow reduces the impinging jet effectiveness, but the presence of the showerhead film hole enhanced the heat transfer. Yang et al. (2014) experimentally and numerically studied the unsteady impingement cooling within a blade leading edge passage and the crossflow effect was observed.

\subsection{Objectives of Current Study}

Extensive studies have focused on jet impingement cooling design. The jet hole geometry has been varied in shape and position; however, the tangential jet with a staggered alignment has not been presented in open literature. The main objectives of this paper are summarized below:
1. Experimentally investigate heat transfer and pressure drop for leading edge impingement with two jet configurations: the normal jet and the staggered, tangential jet. Effects of jet Reynolds number, jet hole arrangement, and the number of jets will be considered.

2. Use CFD to numerically complement the present experimental results. The numerical simulation is also expected to visualize the temperature distributions in the leading edge impingement cooling designs.

3. Evaluate two different approaches to define the driving fluid temperature for jet impingement; the fluid temperature is measured within the supply plenum and the impingement cavity.

\section{EXPERIMENTAL SETUP AND PROCEDURES}

\subsection{Leading Edge, Jet Impingement Test Section}

A schematic of the experimental assembly is given in Fig. 1. A compressed air system supplies the impingement jet flow. A regulator and orifice meter are used to control and measure the flow rate. A pipe heater connected with a transformer is used to heat the flow to around $45-55^{\circ} \mathrm{C}$. A three-way valve is connected to divert airflow to the bypass line before it is heated to the desired temperature. The target surface, a half cylinder $(\mathrm{OD}=6.35 \mathrm{~cm}$, ID $=5.08 \mathrm{~cm})$, is fully covered with a thinlayer, liquid crystal sheet (wideband, $30^{\circ} \mathrm{C}-35^{\circ} \mathrm{C}$ range). A digital camera captures liquid crystal images, and two illuminating lights are equipped for the transient liquid crystal measurement.

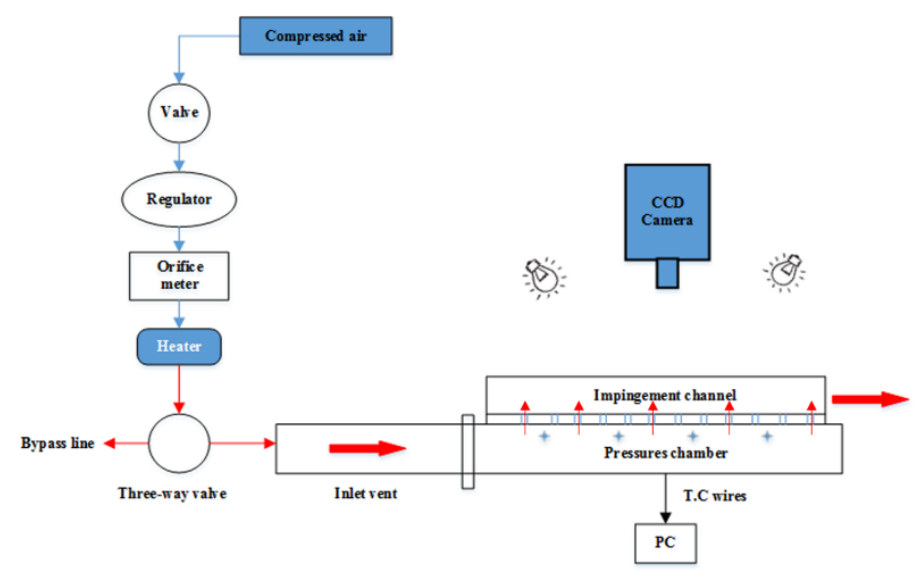

Fig. 1 Overview of experimental setup.

The tested model mainly consists of a rectangular plenum, an impingement plate, and a semi-cylindrical target surface. As shown in Fig. 2, all spent air exits the impingement cavity opposite of the entrance. The material of the test section is plexiglass, transparent and low conductivity, which is necessary for the transient liquid crystal, internal heat transfer measurement. The camera viewing angle is fixed at $45^{\circ}$.
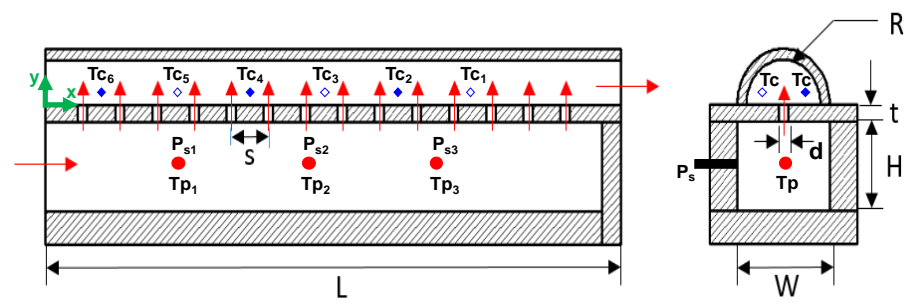

Fig. 2 Test model. 


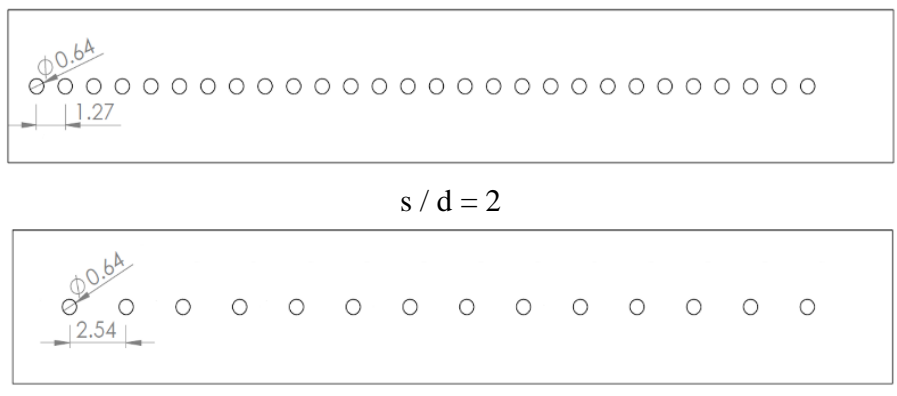

$\mathrm{s} / \mathrm{d}=4$

(a) Normal jets

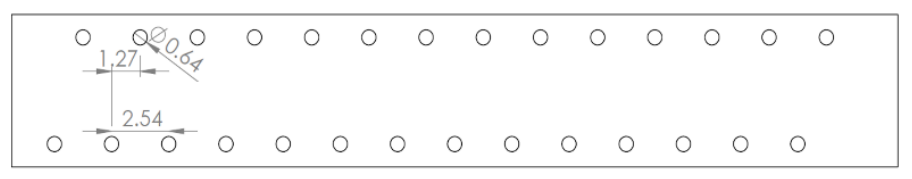

$$
\mathrm{s} / \mathrm{d}=2
$$

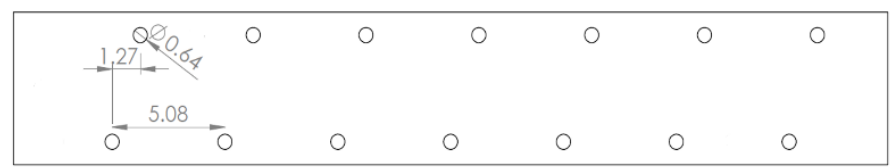

$$
\mathrm{s} / \mathrm{d}=4
$$

(b) Tangential jets

Fig. 3 Impingement jet plate details.

Figure 3 shows the jet plate designs. There are two impingement designs: the normal impinging jet and the staggered tangential impingement jet. The jet hole diameter is fixed at $0.635 \mathrm{~cm}$. The ratio of jet-to-jet spacing at $\mathrm{s} / \mathrm{d}=2$ and 4 are tested for both cases. The ratio of jet-to-target surface spacing is fixed at $\mathrm{z} / \mathrm{d}=4$ (for the normal jet).

As shown in Fig. 3, with $\mathrm{s} / \mathrm{d}=2$, a total of 28 holes span the length of the jet plate for both the normal jet and tangential jet configurations. With $\mathrm{s} / \mathrm{d}=2$, jet Reynolds numbers ranging from 5,000 to 15,000 are investigated. When the jet-to-jet spacing increases to $\mathrm{s} / \mathrm{d}=4$, the number of jets is reduced to 14 . To maintain the same mass flow rate between the two configurations, the range of Reynolds numbers increases to 10,000 to 30,000 (same flow rate for half as many holes at a constant diameter). Table 1 summaries the impingement geometry and flow conditions for this investigation.

There are 3 thermocouples (Tp1, Tp2, and Tp3) evenly distributed along the pressurized plenum chamber to measure the mainstream temperature as shown in Fig. 2; meanwhile 6 thermocouples (Tc1 to Tc6) are fixed on the impingement plate and inserted into the impinging channel to measure the jet mixing temperature, with a distance of $1.27 \mathrm{~cm}$ from the centerline, as shown in Fig. 4. All thermocouples used to measure fluid temperatures are constructed of 30 AWG thermocouple wire. With a thermocouple bead of approximately $0.5 \mathrm{~mm}$, the time constant for the thermocouples ranges from approximately $0.5-1.0$ second. The duration of the transient test is approximately 30 seconds, so this minor delay in the thermocouple response is negligible.

\subsection{Experimental Method}

A transient liquid crystal measurement technique is used for the measurement of the internal heat transfer coefficients (Ekkad and Han, 2000). A liquid crystal sheet $\left(30^{\circ} \mathrm{C}-35^{\circ} \mathrm{C}\right.$ range $)$ is attached to the leading
Table 1 Summary of geometry and flow conditions.

\begin{tabular}{|c|c|c|c|c|}
\hline & \multicolumn{2}{|c|}{ Normal Jets } & \multicolumn{2}{c|}{ Tangential Jets } \\
\hline $\mathrm{R} / \mathrm{d}$ & \multicolumn{2}{|c|}{4} & \multicolumn{2}{c|}{4} \\
\hline $\mathrm{z} / \mathrm{d}$ & \multicolumn{2}{|c|}{4} & \multicolumn{2}{c|}{1.4} \\
\hline $\mathrm{t} / \mathrm{d}$ & \multicolumn{2}{|c|}{1.4} & 28 & 4 \\
\hline $\mathrm{s} / \mathrm{d}$ & 2 & 4 & 5,000 & 10,000 \\
\hline $\mathrm{N}$ & 28 & 14 & 10,000 & 20,000 \\
& 5,000 & 10,000 & 15,000 & 30,000 \\
$\mathrm{Re}$ & 10,000 & 20,000 & 30,000 & \multicolumn{3}{c}{} \\
& 15,000 & \multicolumn{3}{c}{} \\
\hline
\end{tabular}

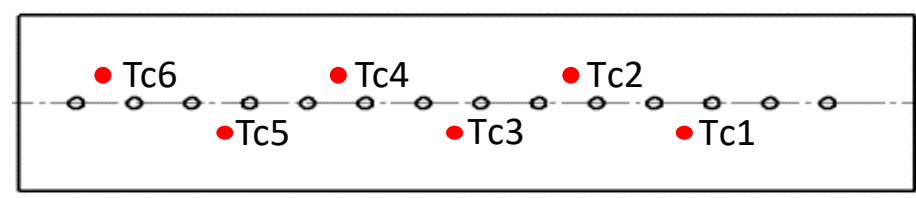

Fig. 4 Thermocouple locations within impingement channel.

edge inner surface to measure the surface temperature. With this "wideband" liquid crystal, a full hue-based method is used to determine the surface heat transfer coefficients. The test initiates with the air is diverted to the supply plenum. After approximately 30 seconds of the air flowing through the test section and impinging on the target surface, a single image is taken of the concave target surface. The entire spectrum of "color" is visible on the target surface, so from the temperature - hue calibration, the temperature at each pixel on the surface can be determined at the set time of 30 seconds.

A calibration test is performed to obtain the hue-temperature profiles. As shown in Fig. 5, the calibration unit consists of a half-cylindrical aluminum tube $(\mathrm{OD}=5.08 \mathrm{~cm}, \mathrm{ID}=3.81 \mathrm{~cm})$, a silicone rubber heater and 6 thermocouples inserted in the tube. The full calibration details are available from Wang et al. (2018).

Figure 6 shows the hue-to-temperature calibration profiles. With the camera and light position fixed, the observed hue varies around the circumference of the cylindrical target surface. Therefore, a more rigorous calibration is required to account for the hue sensitivity relative to the camera position. With the wide-band liquid crystal, the temperature must be known for every hue value; therefore, the full range of color must be calibrated.

The internal, local heat transfer coefficients can be obtained by measuring the target surface temperature and solving the onedimensional transient heat conduction equation in a semi-infinite wall, as shown Eq. (1). In this equation, $T_{w}$ varies across the surface, at a given instant in time, t. This contrasts the transient method utilizing a narrowband liquid crystal test, where the time to reach a given hue / temperature is measured ( $T_{w}$ is held constant, but t varies in Eq. (1)).

$$
\frac{T_{w}-T_{i}}{T_{m}-T_{i}}=1-\exp \left(\frac{h^{2} a t}{k_{s}^{2}}\right) \operatorname{erfc}\left(\frac{h \sqrt{a t}}{k_{s}}\right)
$$

As $T_{m}$ (reference fluid temperature) is time-dependent, the variation of $T_{m}$ is divided into a series of the small discrete time steps. Thus, Eq. (1) can be expressed by the following Eq. (2):

$$
T_{w}-T_{i}=\sum_{j=1}^{N}\left[1-\exp \left(\frac{h^{2} a\left(t-\tau_{j}\right)}{k_{s}^{2}}\right) \operatorname{erfc}\left(\frac{h \sqrt{a\left(t-\tau_{j}\right)}}{k_{s}}\right)\right]\left[\Delta T_{m, j}\right]
$$




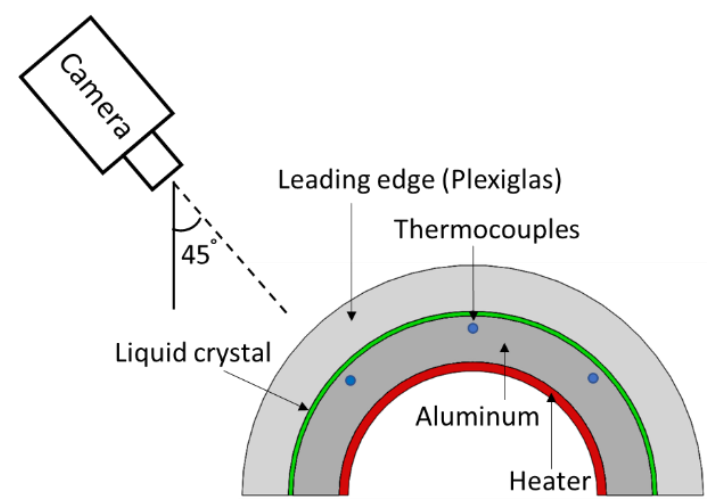

Fig. 5 Details of camera and liquid crystal calibration.

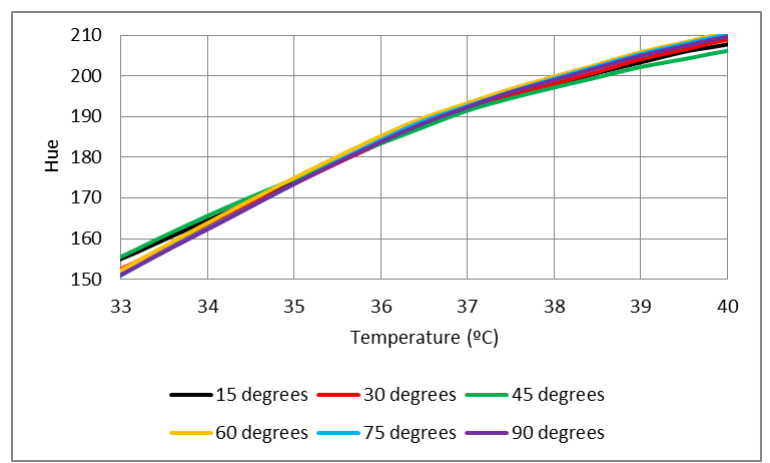

Fig. 6 Calibration curves at different locations on the cylindrical target surface.

The above equation indicates that the calculation of local heat transfer coefficients depends on the selection of reference temperature $\left(T_{m}\right)$. To investigate the sensitivity of the target surface heat transfer to the driving fluid temperature $\left(T_{m}\right)$, the surface heat transfer coefficient is calculated based on two separate fluid temperatures. First, as common to impingement studies, the measured fluid temperature is taken as the fluid temperature entering in the jet orifices (inside the plenum cavity). To account for the effect of spent air and crossflow, the surrounding air within the impingement cavity is also measured (Tc1 - Tc6), and the surface heat transfer coefficients are calculated based on this temperature. The results for these two methods will be compared.

Equations 1 and 2 provide the solution to the one-dimensional, transient conduction equation for a semi-infinite solid exposed to a convection boundary. The equations are provided in Cartesian coordinates; however, transient heat transfer occurs on a concave model. Based on the analysis of Buttsworth and Jones (1997), the Cartesian solution can be applied to a cylindrical geometry cautiously depending on the Biot and Fourier numbers for the experiment. The Biot number of the current plexiglass surface is greater than 100, and the relatively short duration of the test yields a Fourier number of approximately 0.005 . Given these parameters, the error caused by using the Cartesian equation is less than $1 \%$; therefore, the Cartesian solution provides an accurate representation of heat transfer through the concave leading edge model.

From the Eq. 2, the local heat transfer coefficient can be determined on the target surface. The calculated heat transfer coefficient can be normalized, and presented as the Nusselt number. Based on the characteristic length of the jet diameter, the non-dimensional Nusselt number is shown in Eq. 3. Depending on the method used to calculate the heat transfer coefficient (Eq. 2), the thermal conductivity of the air in Eq. 3 is evaluated at the same temperature (either based on the plenum temperature or the impingement cavity temperature). If the reference temperature is based on the plenum temperature, the thermal conductivity of the air is evaluated at the instant in time the surface temperature is recorded and at the average of the three supply plenum thermocouples. Likewise, when the impingement temperature is used as the reference temperature, the thermal conductivity is evaluated at the average temperature of the six thermocouples in the impingement cavity.

$$
N u=\frac{h d}{k_{m}}
$$

From the method proposed by Kline and McClintock (1953), the experimental uncertainty of the target surface heat transfer coefficient is estimated to be $9 \%$ of the measured value. The measurement of the air temperature with thermocouples and the measurement of the set test time of 30 seconds contribute to this value. The uncertainty of the temperature measurements is estimated to be $2.5 \%$ of the measured value. Each test is run for approximately 30 seconds, so the maximum uncertainty of the time measurements is estimated to be $2 \%$. Combining these measurement uncertainties with an approximate uncertainty of $2 \%$ for all measured properties, yields the approximate value of $9 \%$ for the overall uncertainty of the measured heat transfer coefficients.

To fully evaluate the thermal performance of the impingement configurations presented in this work, the overall pressure drop through the system is also measured. Three pressure taps are located in the supply plenum, and these correspond to the spatial locations of the air thermocouples placed in the plenum (Fig. 2). For all flow cases, minimal variation is observed between these static pressure measurements, so the average of the three measurements is used to determine the plenum chamber pressure. This supply pressure is compared to the exhaust pressure at the end of the impingement cavity (atmospheric pressure) to provide an overall $\Delta P$ for the system. Combining this pressure drop with the average fluid velocity at the impingement channel exit, $V_{\text {avg }}$, the pressure loss coefficient, $K$, for the system can be calculated using Eq. 4 .

$$
K=\frac{\Delta P}{\frac{1}{2} \rho V_{a v g}^{2}}
$$

\section{NUMERICAL SETUP AND PROCEDURES}

Transient, conjugate heat transfer simulations were done using ANSYS FLUENT 18.2. Grids, including unstructured meshes, were generated using ICEM CFD. There are 20 prism layers near the walls, with y+ less than 2 . The total number of elements is about 5 million. Figure 7 shows a cross-section of the mesh used for both the normal jet and tangential jet configurations. As shown with the mesh, both the internal fluid volume and all plexiglass surfaces were meshed. The meshing of both the solid and fluid volumes is required to complete the full transient numerical simulations. The basic layout of the gird followed the previous work of Wang et al. (2018). In the prior investigation, the results demonstrated grid independence with 2.5 million elements for a normal jet and 3.5 million elements for the tangential jet. Therefore, the mesh size of 5 million elements (including both the fluid and solid domain), should be sufficiently large to ensure the results are gird independent.

This transient simulation is conducted in parallel with the transient experiment. Therefore, the entire domain (both fluid and solid zones) are initially at a temperature of $23^{\circ} \mathrm{C}$, and the inlet temperature of the fluid is $43^{\circ} \mathrm{C}$. The simulation starts when the hot air begins flowing through the test section. The internal surface of the solid model is coupled with the fluid zone, and the temperature on the external surface of the solid model is $23^{\circ} \mathrm{C}$ (matching the semi-infinite solid assumption of the transient experiment). The simulation runs from 0 to 60 seconds, which is same as the experiments. 


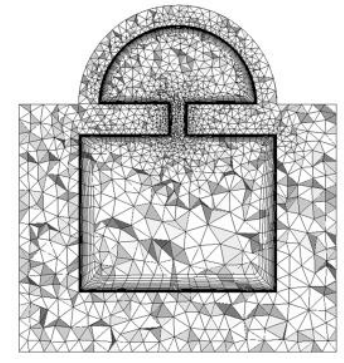

(a) Normal Jet

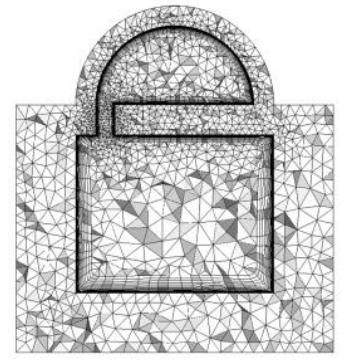

(b) Tangential Jet
Fig. 7 Meshes for both jet configurations of the numerical investigation

The realizable k- $\varepsilon$ (RKE) turbulence model with enhanced wall treatment is used. Wang et al. (2018) considered two turbulence models for a similar leading edge impingement geometry. The results provided by the RKE model were the closer match to the experimental results (compared to the $\mathrm{k}-\omega$, SST model). With a similar geometry considered in the current investigation, the k- $\varepsilon$, RKE model was also chosen for this computational study.

For comparison to the experimental data, the surface heat transfer coefficient from the simulation is non-dimensionalized as the Nusselt number. At a specific instant in time, the Nusselt number can be calculated using Eq. 5.

$$
N u=\frac{q^{\prime \prime}}{\left(T_{w}-T_{m}\right)} \frac{d}{k_{m}}
$$

The surface heat flux, $q$ "', comes from the solution of the numerical simulation, $T_{w}$ is the target surface temperature, and $T_{m}$ is the average fluid temperature in the semi-cylinder impingement channel at a given time. During the simulation from $t=20 \mathrm{~s}$ to $60 \mathrm{~s}$, the Nusselt number remains constant, so $t=40$ s results are used in this paper. Calculations were assumed to converge when the residuals were on the order of $10^{-8}$ for energy, on the order of $10^{-4}$ for the continuity equation, and on the order of $10^{-5}$ for all other residuals.

\section{RESULTS AND DISCUSSION}

In this section, the heat transfer results obtained by using the TLC method and the CFD simulations for normal jet and tangential with $\mathrm{s} / \mathrm{d}=2$ and $\mathrm{s} / \mathrm{d}=4$ are first presented with Nusselt number contours. Then streamwise averaged Nusselt numbers are plotted to compare the heat transfer level for all cases. Finally, the area-averaged Nusselt number results are summarized for all flow conditions and impingement configurations. As shown in Fig. 5, the camera is positioned on the side of the cylindrical model. With the symmetry plane (apex) of the cylinder corresponding to $90^{\circ}$ and the base of the half cylinder $0^{\circ}$, the camera is located at $45^{\circ}$. The view angle of the camera allows for heat transfer coefficients to be measured over the area ranging from $15^{\circ}$ to $90^{\circ}$. Although multiple thermocouples are available in both the supply plenum and the impingement cavity, the surface heat transfer coefficients are calculated based on the average of either the plenum-side or impingement-side thermocouple groups.

\subsection{Temperature Distributions}

Figure 8 shows the flow temperatures recorded by the thermocouples in the experiment for the case of the normal jet, $\mathrm{s} / \mathrm{d}=4$ and $\mathrm{Re}=20,000$. Here, $\mathrm{Tp}$ is the flow temperature in the plenum, and $\mathrm{Tc}$ is the flow temperature in the impingement channel. With all walls in the channel initially at room temperature, when the hot air is released into the test section, the temperature of the fluid gradually increases with time. Furthermore, it is observed that the temperature decreases from Tp1, Tp2 to Tp3 (from the inlet to the outlet of the plenum supply); the measured

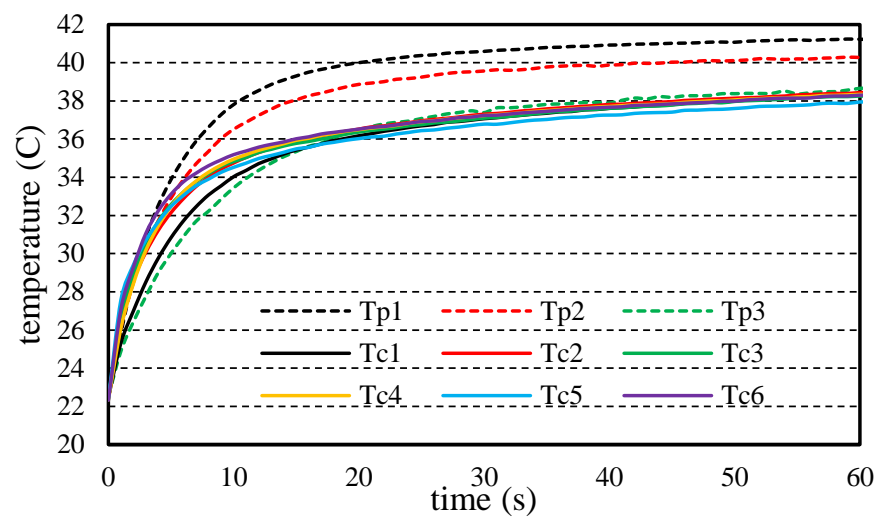

Fig. 8 Temperatures measured by thermocouples for the normal jet configuration $(\mathrm{s} / \mathrm{d}=4, \operatorname{Re}=20,000)$.

channel temperature (Tc1-Tc6) is more uniform than the plenum temperature (Tp1-Tp3).

The CFD simulations can provide more detail of the temperature distribution. Figure 9 shows the temperature field in the plenum and on the test section internal surface at $t=40$ s by CFD. Figure 10 shows the temperature field in the fluid at $\mathrm{t}=40$ s by CFD. With the conjugate calculation, the fluid and solid domains are initially at room temperature. While the thermal conductivity of the walls is low, it is not zero; thus through the transient simulation, a temperature gradient in the fluid and along the walls of the channel is observed. There are 14 slices located in the center of each jet orifice. It is found that the fluid temperature in the impingement channel for the normal jet is higher than that for the tangential jet. The temperature variation in the plenum will affect the calculation for the heat transfer coefficients and should not be neglected. The fluid temperature distributions in Fig. 10 also allow an interesting perspective of the flow development within the plenum and into the impingement cavity. The jets are forced through the jet plate, where a high temperature fluid is clearly observed. As the jet moves from the jet plate toward the curved target surface, the jet temperature decreases as it interacts with the crossflow in the impingement cavity. Near the entrance of the channel, the jets are unaffected by crossflow, and the development of the jet is clearly observed for both the normal and tangential configurations. Progressing through the channel, the jet is less pronounced (indicated by lower temperatures), and the mixing between the jet and the crossflow is very strong.

\subsection{Detailed, Local Nusselt Number Distributions}

Figure 11 and Fig. 12 show detailed local Nusselt number contours for the two jet impingement designs. The average plenum temperature is used as the reference temperature. The results are presented from $\mathrm{x} / \mathrm{d}=4$ to $\mathrm{x} / \mathrm{d}=58$ in the streamwise direction over the entire span, where $\mathrm{x}$ is defined from the supply side of the test section. In this cooling passage, the cross flow in the impingement channel is from the left to the right as shown in the figures.

Figure 11 presents the detailed Nusselt number distributions with $\mathrm{s} / \mathrm{d}=2$ and $\mathrm{N}=28$; the jet Reynolds number varies from 5,000 to 15,000. Results show an increase in the local Nusselt number for an increase in the jet Reynolds number. For the normal jet, Fig. 11 shows the crossflow increases as $\mathrm{x} / \mathrm{d}$ increases. The downstream jets are gradually pushed away from the target surface due to the increasing of crossflow, thus decreasing the local heat transfer. At the distant location, the jets even disappear from the contour because of the increased cross flow. For the tangential jet, half of the total jets (14 impinging jets) are measured on one side. The first jet (closest to the inlet edge) is not presented, while the other 13 jets can be identified. As x/d increases, the downstream jets are deflected in the cross-flow direction. The deflection of the tangential 


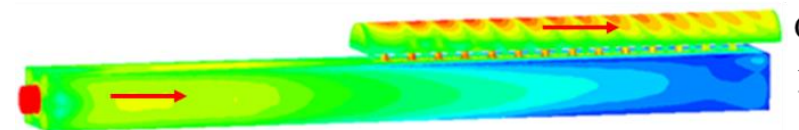

Channel Plenum

(a) Normal jets: $\mathrm{s} / \mathrm{d}=4, \operatorname{Re}=20,000$

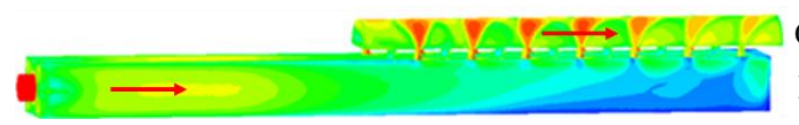

Channel

Plenum

(b) Tangential jets: $\mathrm{s} / \mathrm{d}=4, \mathrm{Re}=20,000$

\section{$\mathrm{T}\left({ }^{\circ} \mathrm{C}\right)$}

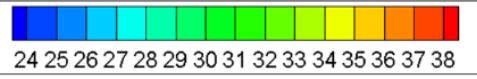

Fig. 9 Predicted temperature distributions on the target surface at $\mathrm{t}=40 \mathrm{~s}(\mathrm{CFD})$.

jet is smaller than the normal jet. It is because the jet hole spacing for the tangential jet is larger than the normal jet, and the distance between the jet hole and the target surface for the tangential jet is smaller than the normal jet. The development of the crossflow within the impingement cavity varies depending on the impingement geometry. The boundary layer development associated with the crossflow leads to relatively low momentum in the corner near the jet plate. Due to the decreased momentum of the crossflow, the tangential jet ensuing from the orifice in this region is able to more effectively penetrate the crossflow. Therefore, the tangential jets experience less deflection than the normal jets which must pass through the core of the crossflow.

Figure 12 presents the detailed Nusselt number distributions with $\mathrm{s} / \mathrm{d}=4$ and $\mathrm{N}=14$; the jet Reynolds number varies from 10,000 to 30,000. The local heat transfer increases with increasing jet Reynolds number and decreases with increasing $\mathrm{x} / \mathrm{d}$ for both designs. For the normal jet, the flow directly impinges onto the target surface, creating circular and higher heat transfer regions along the test surface centerline. As $\mathrm{x} / \mathrm{d}$ increases, a decrease of heat transfer is observed, but the distribution is more uniform on the surface. Jets near the exit, where $\mathrm{x} / \mathrm{d}$ is large, fail to directly impinge on the target surface. For the tangential jet, seven tangential jets on one side are observed. They create the tear-drop higher heat transfer region on the test surface. The tangential jets enter the impingement channel from both sides, and they are bent to follow the curvature of the target surface.

Figure 13 compares the detailed, local Nusselt number distributions from the experiment and the CFD for the two jet impingement designs using the impingement channel temperature as the reference temperature. Due to the viewing angle of the single camera used in the experiment, the detailed heat transfer coefficient distributions are limited to the range of $15^{\circ}-90^{\circ}$, with $90^{\circ}$ corresponding to the apex of the cylindrical target surface. This limitation does not exist for the numerical simulations, therefore, the entire surface $\left(0^{\circ}-180^{\circ}\right)$ is provided for the simulations. Similar to previous results, the local heat transfer decreases with increasing $\mathrm{x} / \mathrm{d}$ for both jet impingement designs due to the crossflow effects. However, the results show higher local heat transfer compared to the results presented in Figs. 11 and 12 for both normal and tangential jets. Also shown in Fig. 12, as the jet Reynolds number and s/d increase, the total coolant flow rate supplied to the system is unchanged. At a fixed mass flow rate, increasing the spacing of the jets allows for overall, higher heat transfer, for both the normal and tangential jets.

\subsection{Streamwise Averaged Nusselt Number Distributions}

Figure 14 shows the streamwise averaged Nusselt number distributions with $\mathrm{s} / \mathrm{d}=2$, corresponding to the contours in Fig. 11. It shows the increase of jet Reynolds number provides an increasing streamwise averaged Nusselt number for the entire channel. For the normal jet, the heat transfer level varies from peak to valley within a narrow range. As

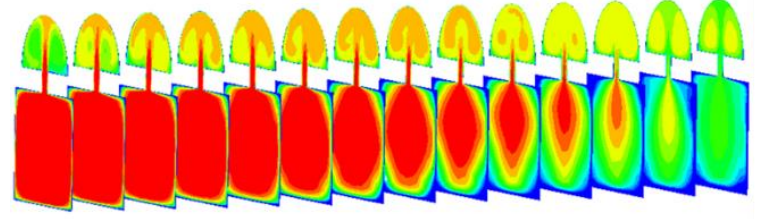

Channel

(a) Normal jets: $\mathrm{s} / \mathrm{d}=2, \mathrm{Re}=10,000$

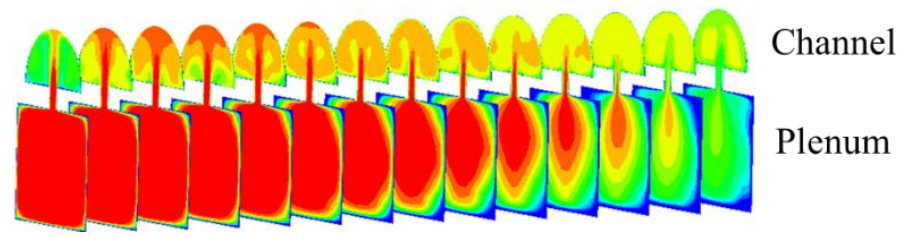

(b) Normal jets: $\mathrm{s} / \mathrm{d}=4, \mathrm{Re}=20,000$

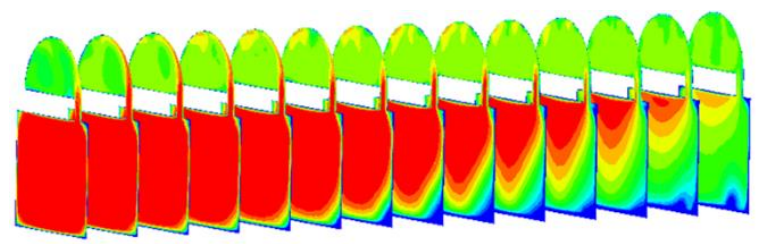

Channel

(c) Tangential jets: $\mathrm{s} / \mathrm{d}=2, \mathrm{Re}=10,000$

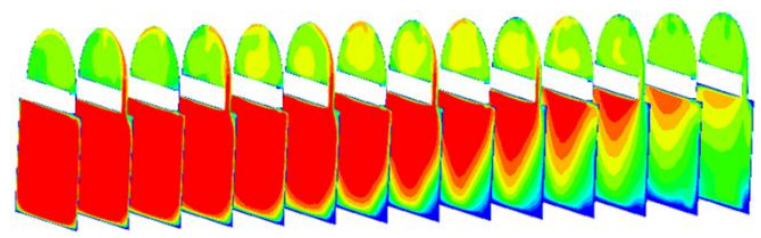

Channel

(d) Tangential jets: $\mathrm{s} / \mathrm{d}=4, \operatorname{Re}=20,000$

Plenum

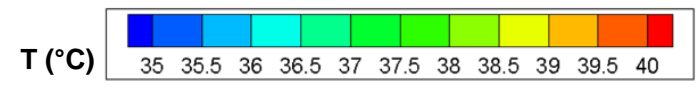

Fig. 10 Predicted temperature distributions of the coolant at $t=40 \mathrm{~s}$ (CFD).

$\mathrm{x} / \mathrm{d}$ increases, the heat transfer distributions become uniform (individual jets are less distinguishable). For the tangential jet, the location of the upstream jet can be indicated by the peak values. The heat transfer levels oscillate from peaks to valleys, with the difference between the peak and valleys decreasing as $\mathrm{x} / \mathrm{d}$ increases. At $\mathrm{x} / \mathrm{d}>40$, the heat transfer distributions are quite stable and uniform. Figure 14(a) and Fig. 14(b) show that the averaged Nusselt number of both the normal jet and the tangential jet are approximately 20,30 and 50 for the three Reynolds numbers.

Figure 15 shows the streamwise averaged Nusselt number distributions with $\mathrm{s} / \mathrm{d}=4$, corresponding to the contours in Fig. 12. The heat transfer levels increase with the increase in jet Reynolds number for both designs. For the normal jet, the Nusselt numbers oscillate and decrease along the flow direction. The impinging jets near the exit are affected by the upstream crossflow; thus the Nusselt numbers decrease toward the exit direction. As $\mathrm{x} / \mathrm{d}$ increases, the heat transfer fluctuation decreases but they oscillate about the same average value. Figure 15(a) and Fig. 15(b) show that due to the effect of the jet impingement design, the normal jets are more deflected by the crossflow; thus, the crossflow effect decreases the impingement effect of the downstream jets. However, the crossflow effects on the tangential jet are relatively mild.

Figure 14(a) and Fig. 15(a) presents the effects of the number of the jet for the normal jet case. At equivalent mass flow rate condition, the jet Reynolds number of the 28-hole design $(\mathrm{s} / \mathrm{d}=2)$ is decreased by half of the 14-hole design $(\mathrm{s} / \mathrm{d}=4)$. Therefore, the $\mathrm{s} / \mathrm{d}=4$ cases provide higher heat transfer results. 


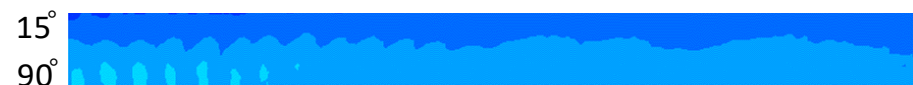

(a) Normal jets: $\operatorname{Re}=5,000$

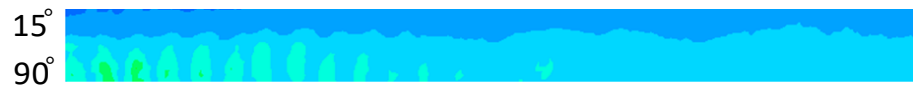

(b) Normal jets: $\mathrm{Re}=10,000$

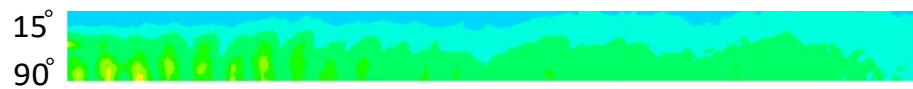

(c) Normal jets: $\operatorname{Re}=15,000$

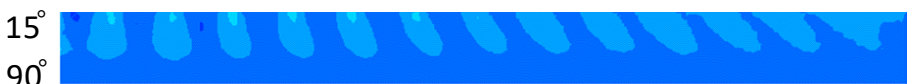

(d) Tangential jets: $\operatorname{Re}=5,000$

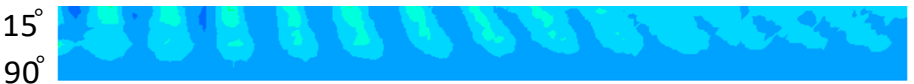

(e) Tangential jets: $\operatorname{Re}=10,000$

$15^{\circ}$

$90^{\circ}$

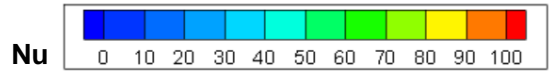

Fig. 11 Experimental Nusselt number distributions for $\mathrm{s} / \mathrm{d}=2$ (reference temperature inside the plenum).

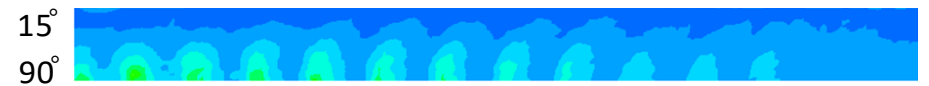

(a) Normal jets: $\operatorname{Re}=10,000$

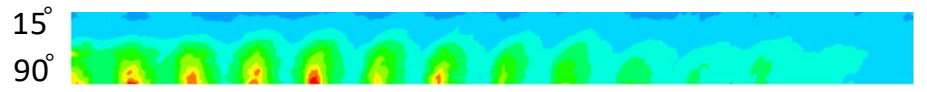

(b) Normal jets: $\operatorname{Re}=20,000$

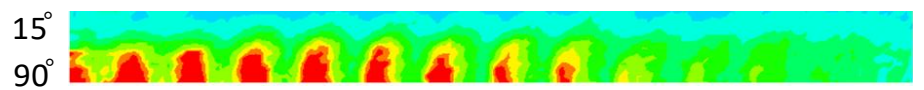

(c) Normal jets: $\operatorname{Re}=30,000$

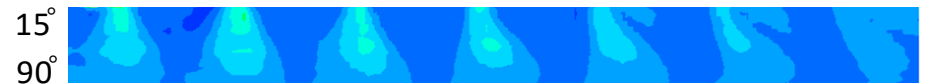

(d) Tangential jets: $\operatorname{Re}=10,000$

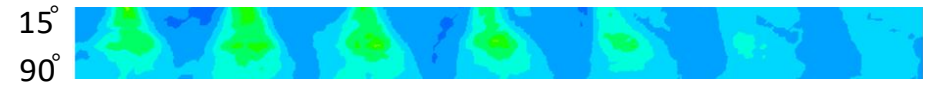

(e) Tangential jets: $\operatorname{Re}=20,000$

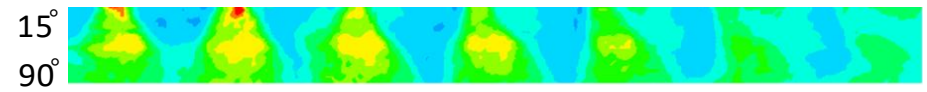

(f) Tangential jets: $\operatorname{Re}=30,000$

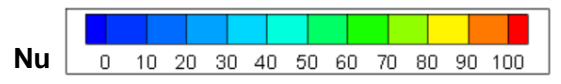

Fig. 12 Experimental Nusselt number distributions for $\mathrm{s} / \mathrm{d}=4$ (reference temperature inside the plenum).

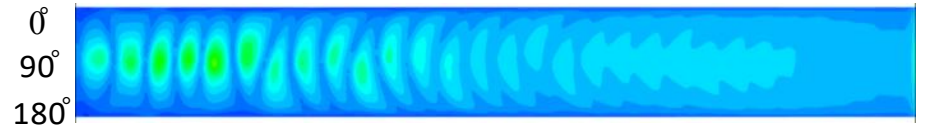

(a) CFD - Normal jets: $\mathrm{s} / \mathrm{d}=2, \mathrm{Re}=10,000$

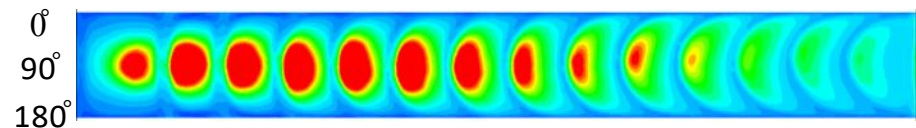

(b) CFD - Normal jets: $\mathrm{s} / \mathrm{d}=4, \mathrm{Re}=20,000$

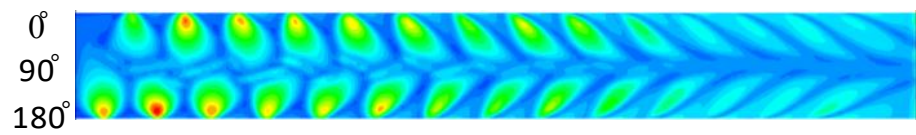

(c) CFD - Tangential jets: $\mathrm{s} / \mathrm{d}=2, \mathrm{Re}=10,000$

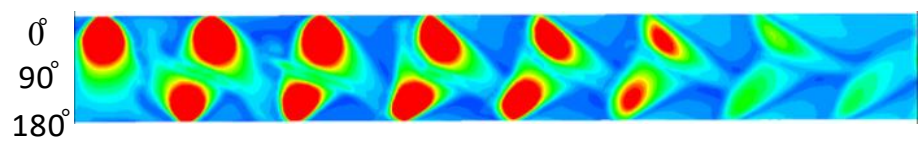

(d) CFD - Tangential jets: $\mathrm{s} / \mathrm{d}=4, \operatorname{Re}=20,000$

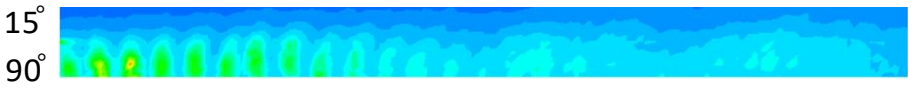

(e) Experimental - Normal jets: $\mathrm{s} / \mathrm{d}=2, \mathrm{Re}=10,000$

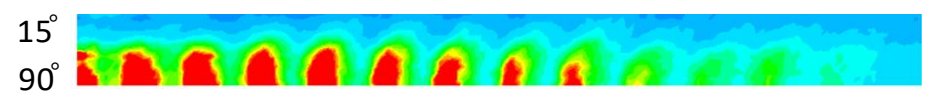

(f) Experimental - Normal jets: $\mathrm{s} / \mathrm{d}=4, \mathrm{Re}=20,000$

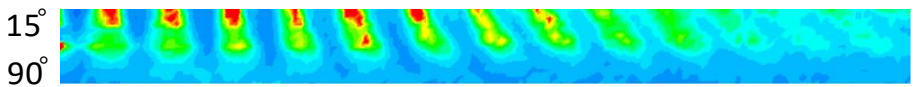

(g) Experimental - Tangential jets: $\mathrm{s} / \mathrm{d}=2, \mathrm{Re}=10,000$

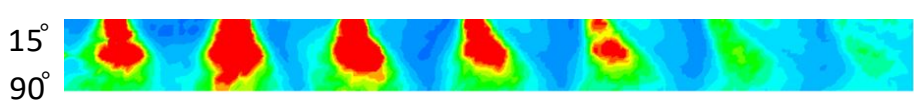

(h) Experimental - Tangential jets: $\mathrm{s} / \mathrm{d}=4, \mathrm{Re}=20,000$

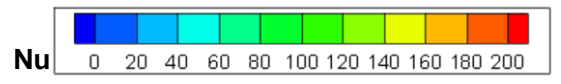

Fig. 13 Comparison of the Nusselt number distributions obtained experimentally and computationally (reference temperature inside the impingement channel). 


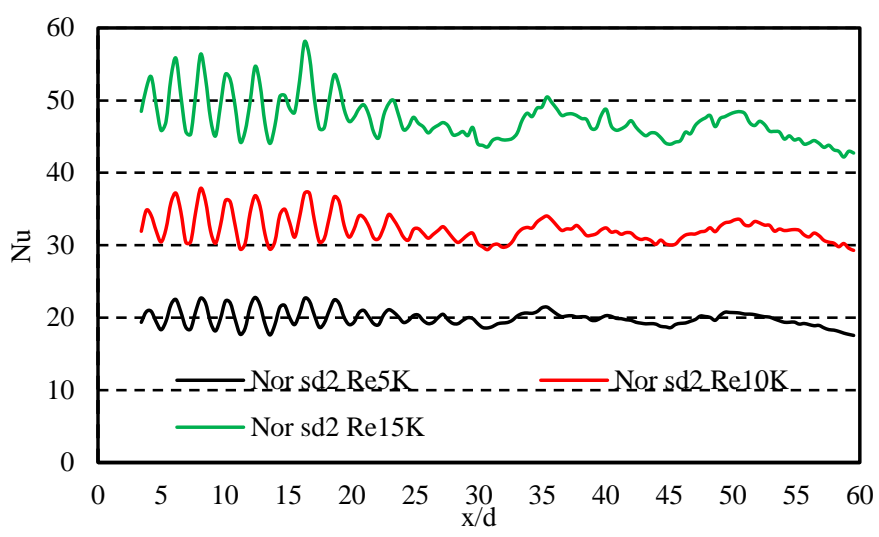

(a) Normal jets

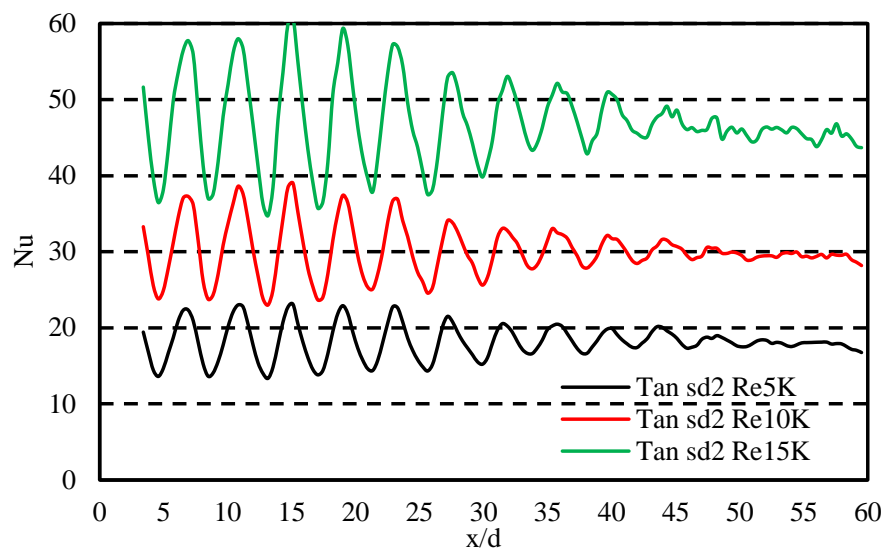

(b) Tangential jets

Fig. 14 Streamwise averaged Nusselt numbers for $\mathrm{s} / \mathrm{d}=2$ (reference temperature inside the plenum).

Figure 16 and Fig. 17 show the streamwise averaged Nusselt number distributions for $s / d=2$ and 4 . The values shown in these figures are referenced to the air temperature measured within the impingement cavity. The curves show the similar heat transfer distributions as the curves using the reference temperature in the plenum as given in Fig. 14 and Fig. 15; however, the local heat transfer values can be much higher by 2-3 times for each case. This can be explained by Fig. 8 and Eq. 1, it shows the temperature in the impingement channel is lower than the temperature in the plenum, then the heat transfer coefficients using reference in the impingement channel are higher.

\subsection{Streamwise Averaged Nusselt Number Comparison with CFD}

The comparisons of the results for normal jet and tangential jet from experiments and CFD are shown in Fig. 18. To provide a fair comparison between the data sets, the streamwise averages for the both the experiments and simulations are completed over the range of $15^{\circ}-90^{\circ}$. The agreement between the streamwise averaged Nusselt numbers from experiments and CFD is relatively good. Although there are some overpredictions for peak values, the decreasing trend of the Nusselt number created by the crossflow effect is well predicted. The greatest deviation between the experimental and numerical results occurred for the normal jet with $\mathrm{s} / \mathrm{d}=2$. In this case, the flow field is quite complex due to the low jet Reynolds number and too many jets ( 28 jets). It is satisfying that the $s / d=4$ cases, more close to the actual design, show excellent agreement with the experimental results. Overall, the present CFD model has an excellent capability to predict the heat transfer for leading edge normal jet and the tangential jet impingement.

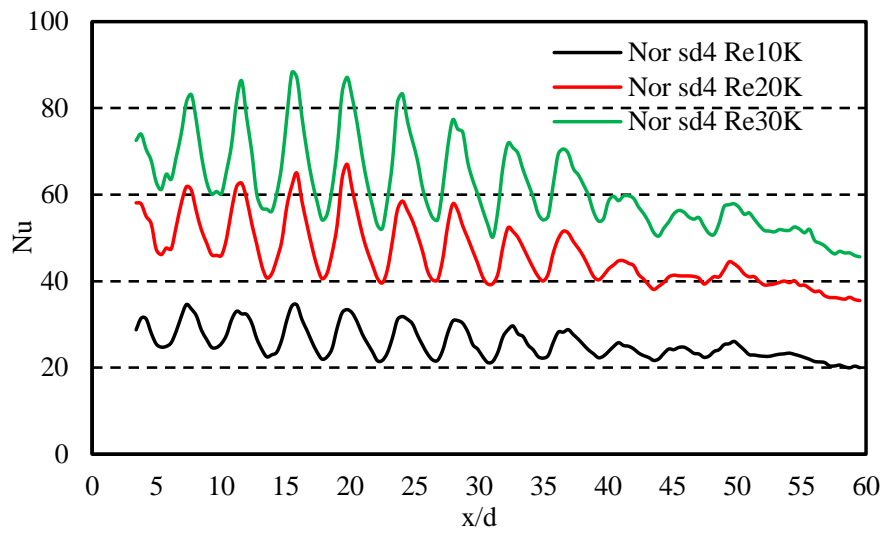

(a) Normal jets

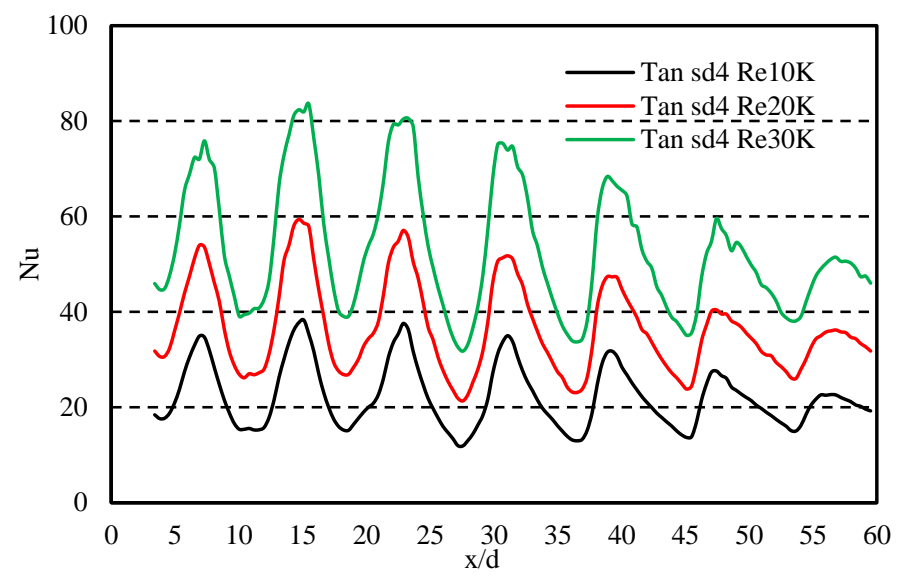

(b) Tangential jets

Fig. 15 Streamwise averaged Nusselt numbers for $\mathrm{s} / \mathrm{d}=4$ (reference temperature inside the plenum).

\subsection{Area Averaged Nusselt Numbers}

Figure 19 shows the area-averaged Nusselt numbers comparison for all cases $\left(15^{\circ}<\theta<90^{\circ}\right)$ with two reference temperatures. Referring to either the detailed distributions (Fig. 12) or the streamwise average plots (Figs. $13-17$ ), both the experimental and numerical results show the clear deflection of the jets as the crossflow builds moving from left-toright through the impingement cavity. The effect of this crossflow is clearly demonstrated by comparing the surface average heat transfer coefficients to those predicted by the correlation presented by Chupp et al. (1969). While the limits of this leading edge correlation do not fully encompass the flow conditions of the current investigation $(3,000 \leq \operatorname{Re} \leq 15,000 ; 4 \leq \mathrm{s} / \mathrm{d} \leq 16)$, Table 2 serves as an indication of how significantly the target surface heat transfer is effected by crossflow. To match the correlation, the results shown are based on the plenum temperature. While the leading edge geometry varies from the one used in this study, Taslim et al. (2001a) also observed a similar drop in the surface heat transfer enhancement in the presence of crossflow within the impingement channel.

The area-averaged Nusselt numbers calculated using the reference temperature in the impingement channel are greater than the results calculated using the reference temperature in the supply plenum by up to 2 times. For each case, the area-averaged Nusselt numbers increase with the increasing Reynolds number. Then the area-averaged heat transfer of $\mathrm{s} / \mathrm{d}=4$ cases are higher than the $\mathrm{s} / \mathrm{d}=2$. From Fig. 19(a), using the reference temperature in the plenum, it shows the heat transfer performance for the normal jet and the tangential jet can be comparable when $\mathrm{s} / \mathrm{d}=2$ and the jet Reynolds number is low. At the higher jet Reynolds numbers, the normal jet configuration appears to provide 


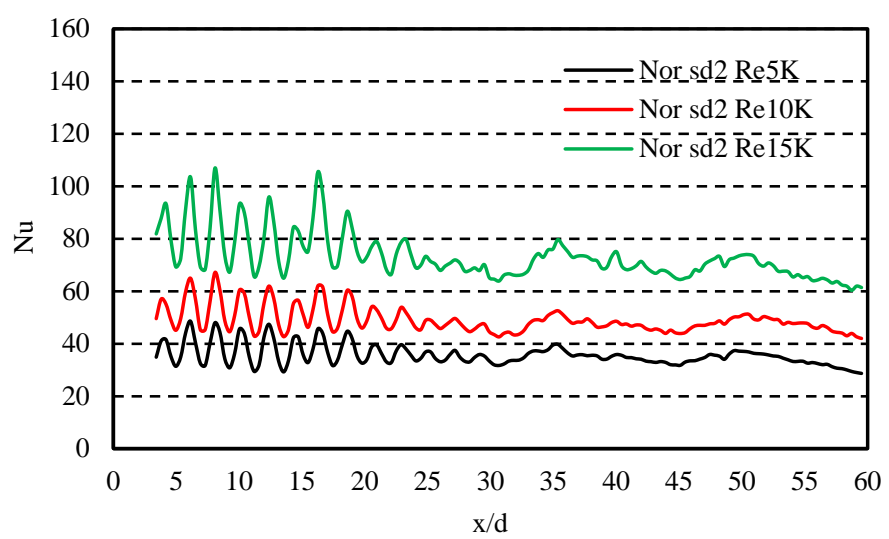

(a) Normal jets

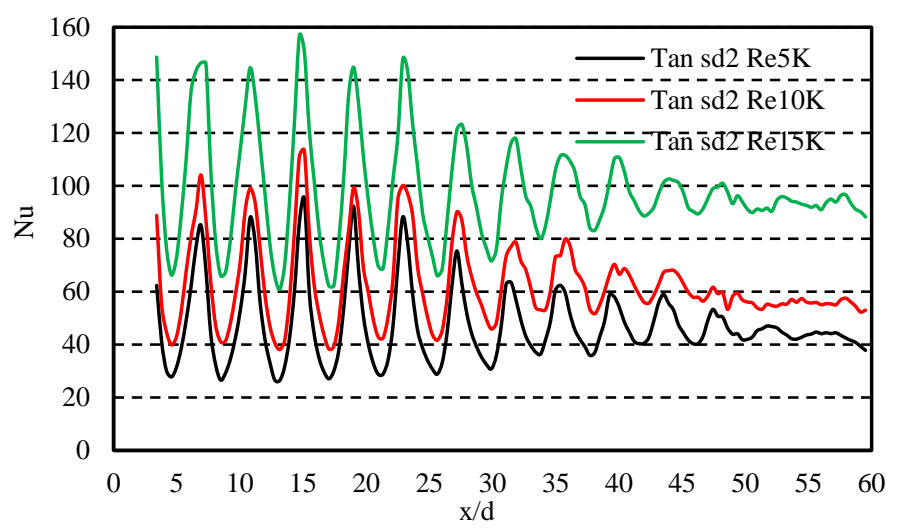

(b) Tangential jets

Fig. 16 Streamwise averaged Nusselt numbers for $\mathrm{s} / \mathrm{d}=2$ (reference temperature inside the impingement channel).

higher heat transfer results. Figure 19(b), using the reference temperature in the impingement channel, shows the tangential jet design provides better cooling performance when $\mathrm{s} / \mathrm{d}=2$; for $\mathrm{s} / \mathrm{d}=4$, the performances of both designs are comparable.

The comparison between the two designs is different, depending on whether the reference temperature is in the plenum or in the impingement channel. It is because the fluid temperature difference between the plenum and the impingement channel for the tangential jet is greater than the normal jet. The tangential jets have less direct interaction with the crossflow. Therefore, the impingement cavity temperature is lower for the configuration with the tangential jets compared to the normal jets. The limited interaction leads to less deflection of the tangential jet compared to the normal jet, but the normal jets yield higher crossflow (impingement cavity) temperatures. When basing the heat transfer coefficients on the impingement cavity temperature, the lower temperature with the tangential jets provides higher heat transfer coefficients on the target surface.

The majority of studies available in open literature use the "jet" or "plenum" temperature as a reference for the calculation of the target surface heat transfer coefficient. Depending on the crossflow conditions and the jet-to-target surface spacing, the temperature of the fluid near the target surface can vary significantly from the temperature measured near the jet plate. Figure 19 demonstrates the surface Nusselt numbers are very sensitive to the fluid temperature used for the heat transfer coefficient calculation. The heat transfer from the target surface is driven by the local bulk fluid temperature, and designers generally need this mixed fluid temperature within the impingement cavity. Designers and researchers, alike, should be cautious of using published data, because the magnitude is dependent on the chosen

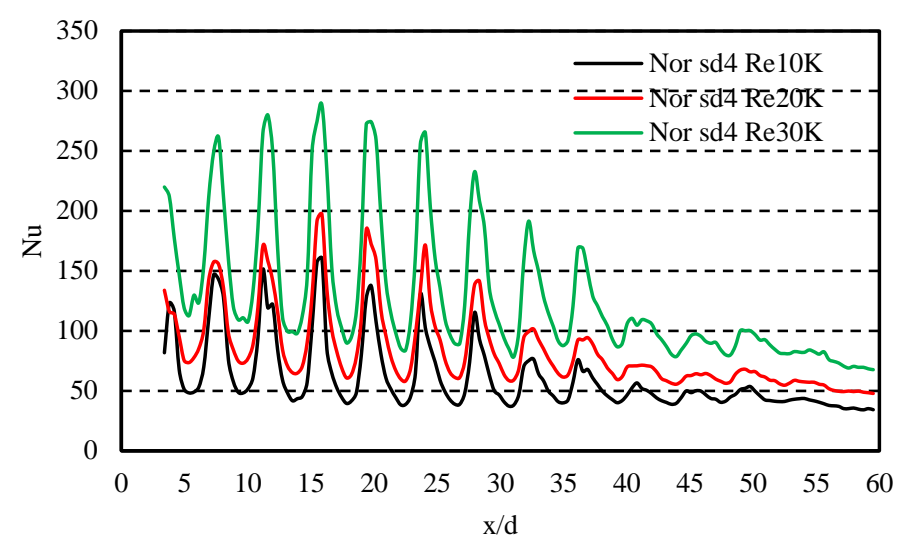

(a) Normal jets

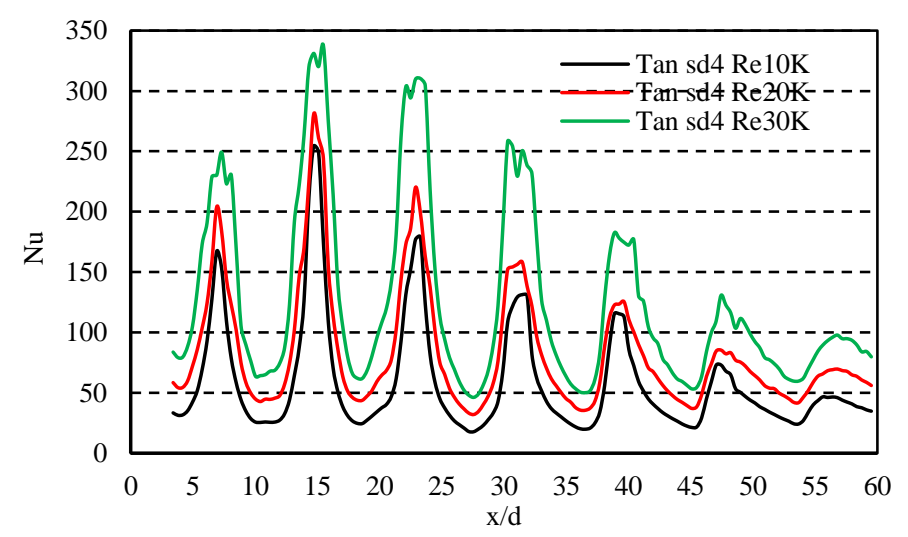

(b) Tangential jets

Fig. 17 Streamwise averaged Nusselt numbers for $\mathrm{s} / \mathrm{d}=4$ (reference temperature inside the impingement channel).

reference temperature. Other groups may choose to define the bulk fluid temperature in a different way, so end users of the data must be aware of the data is obtained.

\subsection{Pressure Loss Coefficients}

Figure 20 shows the pressure loss coefficient profiles between the plenum and the exit of the impingement channel with the variation of jet Reynolds numbers. Figure 20(a), shows the jet Reynolds number has negligible effect on the pressure loss coefficient. In Fig. 20(b), it is shown that increasing the Reynolds number slightly decreases the pressure loss coefficient for the normal jet and a negligible effect on the tangential jet cases. The pressure loss coefficients for the normal jets are always lower than the tangential jet by $15 \%-20 \%$. Lastly, it is evident that the pressure loss coefficients for the cases with $\mathrm{s} / \mathrm{d}=4$ are much higher than the cases with $\mathrm{s} / \mathrm{d}=2$.

Generally, Fig. 19 shows the thermal performance of the normal jet configuration is greater than that of the tangential jet configurations. However, the loss coefficients for the normal jets are significantly lower than those in the arrangement with the tangential jets. Therefore, the normal jet configuration would be more desirable due to the relatively low losses. Comparing the heat transfer coefficients presented in Fig. 13, both configurations provide non-uniform distributions. The spread of the coolant, and the location of maximum heat transfer could further influence the decision on which jet configuration is best suited for a specific cooling need. 


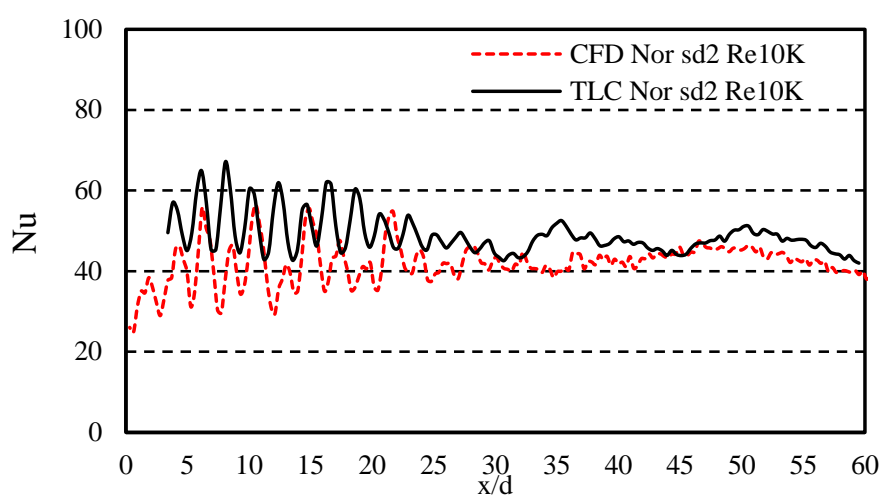

(a) Normal jets $(\mathrm{s} / \mathrm{d}=2, \operatorname{Re}=10,000)$

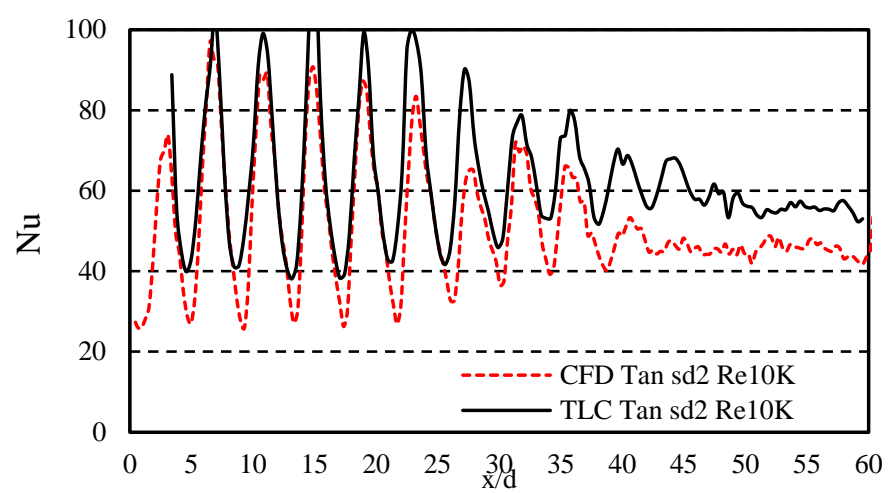

(b) Tangential jets $(\mathrm{s} / \mathrm{d}=2, \operatorname{Re}=10,000)$

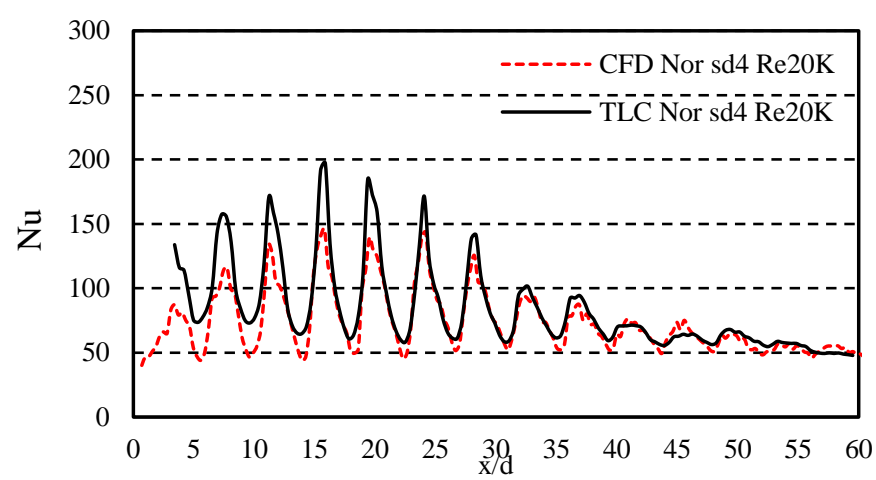

(c) Normal jets $(\mathrm{s} / \mathrm{d}=4, \mathrm{Re}=20,000)$

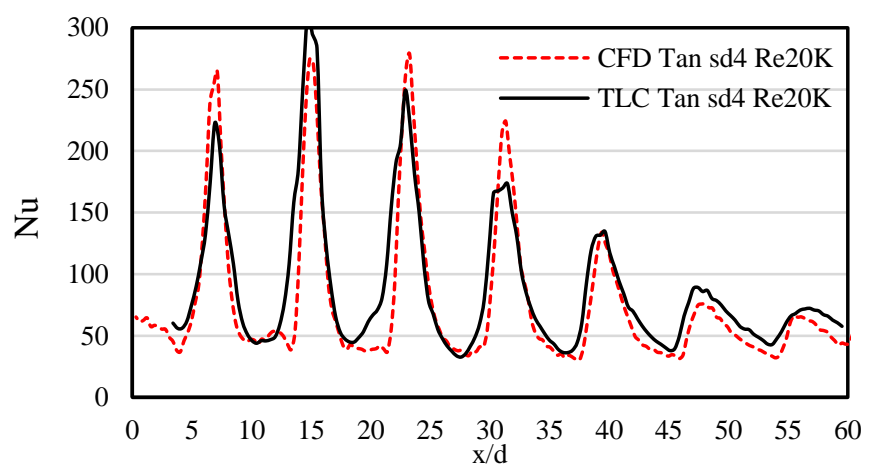

(d) Tangential jets $(\mathrm{s} / \mathrm{d}=4, \mathrm{Re}=20,000)$

Fig. 18 Comparison of the streamwise averaged Nusselt number distributions obtained experimentally and computationally (reference temperature inside the impingement channel).

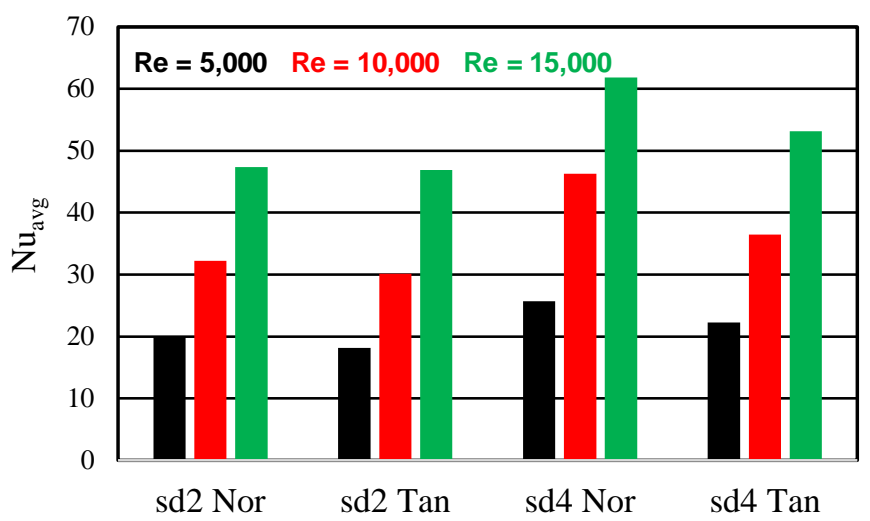

(a) Reference temperature inside the plenum

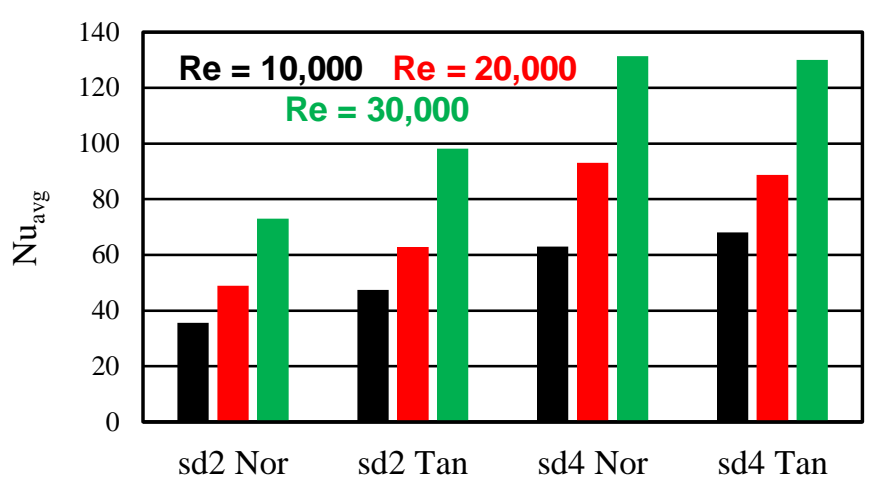

(b) Reference temperature inside the impingement channel

Fig. 19 Area averaged Nusselt numbers.

Table 2 Surface Averaged Heat Transfer Coefficients.

\begin{tabular}{|c|c|c|}
\hline Re & $\begin{array}{c}\text { Measured Surface } \\
\text { Averaged Nusselt Number }\end{array}$ & $\begin{array}{c}\text { Predicted Surface } \\
\text { Averaged Nusselt Number } \\
\text { Chupp et al. (1969) }\end{array}$ \\
\hline \multicolumn{3}{|c|}{$\mathrm{s} / \mathrm{d}=2$} \\
\hline 5,000 & 19.9 & 37.1 \\
\hline 10,000 & 32.2 & 60.3 \\
\hline 15,000 & 47.3 & 80.0 \\
\hline \multicolumn{2}{|c|}{$\mathrm{s} / \mathrm{d}=4$} \\
\hline 10,000 & 25.7 & 46.5 \\
\hline 20,000 & 46.3 & 75.6 \\
\hline 30,000 & 61.8 & 100.4 \\
\hline
\end{tabular}

\section{CONCLUSIONS}

Heat transfer characteristics and pressure loss coefficients were measured within a leading edge impingement model. Normal jets and tangential jets with $\mathrm{s} / \mathrm{d}=2$ and 4 were tested at three different Reynolds numbers. The internal heat transfer distributions were obtained by using the transient liquid crystal method. Temperatures in the plenum and impingement channel were measured and used as the reference temperature for separate calculations of the heat transfer coefficients. In addition, a CFD study was performed and served as a visualization tool to understand and explain the heat transfer behavior. The main conclusions are summarized below: 


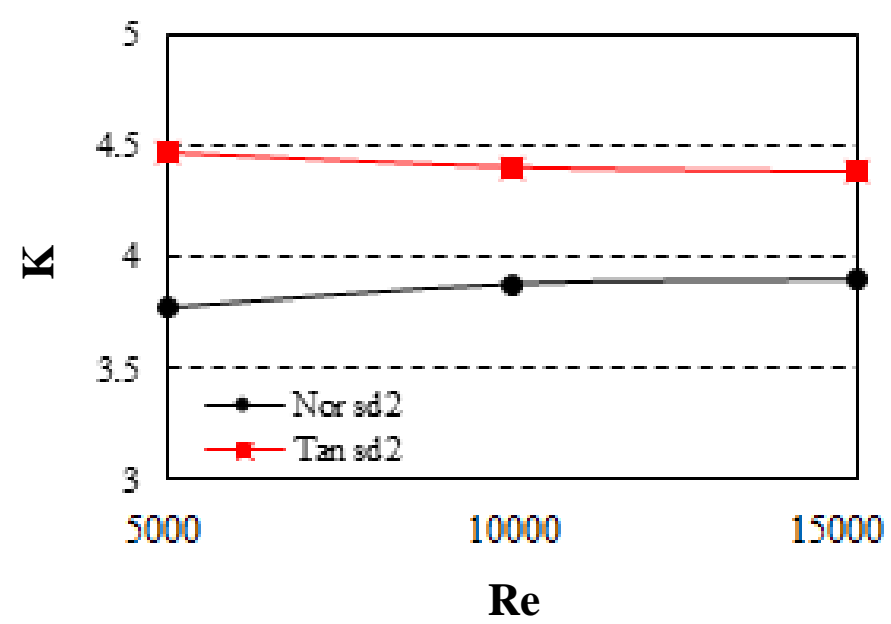

(a) $\mathrm{s} / \mathrm{d}=2$

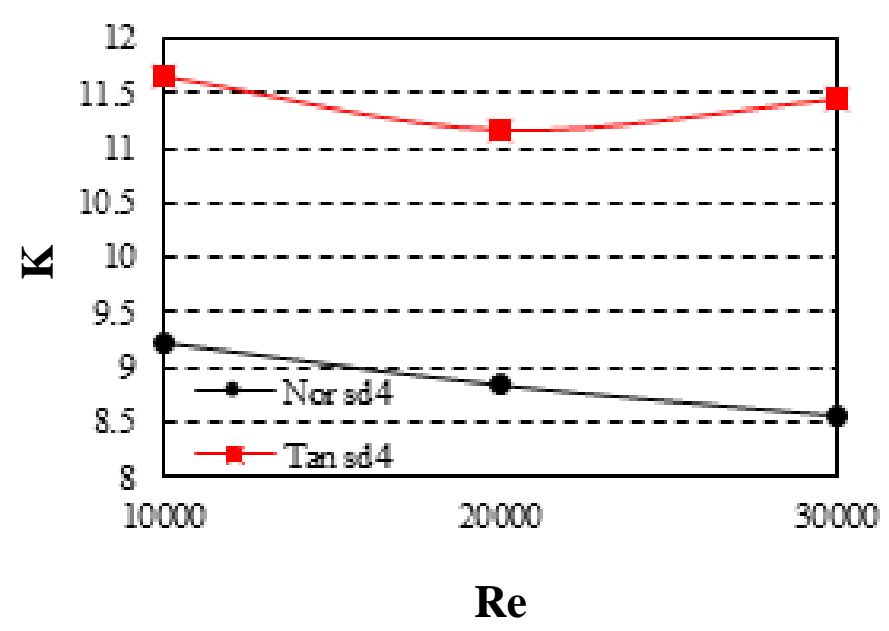

(b) $\mathrm{s} / \mathrm{d}=4$

Fig. 20 Measured pressure loss coefficients.

1. Temperature variation in the cooling passage: The temperature in the plenum is significantly different from that in the impingement channel. Heat transfer coefficients can be calculated based on the fluid temperature in the plenum or the impingement channel. In the present study, Nusselt numbers using the temperature in the impingement channel are 2 times higher than the heat transfer coefficients calculated by the temperature in the plenum.

2. Effect of jet Reynolds number: The heat transfer on the entire impingement surface is dependent on the jet Reynolds number. The local and area-averaged Nusselt numbers increase with the increasing of Reynolds number.

3. Effect of the number of jets: The area-averaged heat transfer levels are significantly affected by the number of jets. At the equivalent mass flow rate condition, jet impingement cases with $\mathrm{s} / \mathrm{d}=4$ (14 jets) provide higher heat transfer than the ones with $\mathrm{s} / \mathrm{d}=2$ ( 28 jets).

4. Effect of jet arrangement: The streamwise averaged heat transfer distributions are significantly affected by the jet arrangement. Jets with staggered, tangential impingement are less affected by the crossflow compared to the normal jet arrangement. The area-averaged heat transfer of the normal jet is generally higher, but future optimization such as, the staggered spacing, row-to-row spacing and the hole shape could be future investigated for the tangential impinging jets.
5. Numerical results: The realizable k- $\varepsilon$ turbulence model shows good capability in predicting the local heat transfer distributions for the leading edge jet impingement with normal jet and tangential jet. The reference temperature is the average temperature in the impingement channel.

6. Pressure drop: The Reynolds number has a mild effect on the pressure drop; meanwhile, the pressure drop for the tangential jet is more significant than the normal jet design.

\section{ACKNOWLEDGEMENTS}

This work was supported through the Marcus C. Easterling endowment fund. The CFD simulations were supported by High Performance Research Computing of Texas A\&M University.

\section{NOMENCLATURE}

$d \quad$ jet hole diameter $(\mathrm{cm}), \mathrm{d}=0.635 \mathrm{~cm}$

$H \quad$ height of plenum, $\mathrm{H}=5 \mathrm{~cm}$

$h \quad$ heat transfer coefficient $\left(\mathrm{W} / \mathrm{m}^{2} \cdot \mathrm{K}\right)$

$k_{m} \quad$ thermal conductivity of coolant $(\mathrm{W} / \mathrm{m} \cdot \mathrm{K})$

$k_{s} \quad$ thermal conductivity of plexiglass target surface $(\mathrm{W} / \mathrm{m} \cdot \mathrm{K})$

$K \quad$ pressure loss coefficient

$L \quad$ length of plenum, $\mathrm{L}=39.37 \mathrm{~cm}$

$N \quad$ number of jet holes

$\mathrm{Nu} \quad$ Nusselt number, $\mathrm{Nu}=\mathrm{hd} / \mathrm{k}_{\mathrm{m}}$

$\Delta p \quad$ pressure drop from supply plenum to impingement exit ( $\mathrm{Pa})$

$q, \quad$ surface heat flux $\left(\mathrm{W} / \mathrm{m}^{2}\right)$

$R \quad$ inner radius of target surface $(\mathrm{cm}), \mathrm{R}=2.5 \mathrm{~cm}$

Re jet Reynolds number, $\operatorname{Re}=\rho V d / \mu$

$\mathrm{s} \quad$ jet - to - jet spacing $(\mathrm{cm})$

$\mathrm{T}_{\mathrm{i}} \quad$ initial surface temperature $\left({ }^{\circ} \mathrm{C}\right)$

$\mathrm{T}_{\mathrm{m}} \quad$ reference fluid temperature $\left({ }^{\circ} \mathrm{C}\right)$

$\mathrm{T}_{\mathrm{w}} \quad$ target surface temperature $\left({ }^{\circ} \mathrm{C}\right)$

$\mathrm{t} \quad$ thickness of jet plate $(\mathrm{cm}), \mathrm{t}=0.9 \mathrm{~cm}$

$\mathrm{t} \quad$ time (seconds)

$\mathrm{V} \quad$ velocity $(\mathrm{m} / \mathrm{s})$

$\mathrm{V}_{\text {avg }} \quad$ average air velocity at the exit of impingement channel $(\mathrm{m} / \mathrm{s})$

$\mathrm{W} \quad$ width of plenum $(\mathrm{cm}), \mathrm{W}=6.7 \mathrm{~cm}$

$\mathrm{x} \quad$ spanwise direction

y streamwise direction

$\mathrm{z} \quad$ jet-to-target surface distance

Greek Symbols

$\alpha \quad$ thermal diffusivity of target surface $\left(\mathrm{m}^{2} / \mathrm{s}\right)$

$\mu \quad$ dynamic viscosity of coolant $(\mathrm{Pa} \cdot \mathrm{s})$

$\theta \quad$ angle around target surface $\left(^{\circ}\right)$

$\rho \quad$ density of coolant $\left(\mathrm{kg} / \mathrm{m}^{3}\right)$

$\tau_{j} \quad$ time step (s)

\section{REFERENCES}

Al-Sanea. S.A., 1992, "A numerical study of the flow and heat transfer characteristics of an impinging laminar slot-jet including crossflow effects," International Journal of Heat and Mass Transfer, 35(10), 25012513. https://doi.org/10.1016/0017-9310(92)90092-7

Amano, R.S. and Sundén, B, 2014, Impingement Jet Cooling in Gas Turbines, WIT Press.

Attalla, M.A.M., 2005, Experimental Investigation of Heat Transfer Characteristics Form Arrays of Free Impinging Circular Jets and Hole Channels, Ph.D. thesis, Uni-Magdeburg, Germany.

Azad, G.M., Huang, Y., and Han, J.C., 2000, “Jet Impingement Heat Transfer on Dimpled Surfaces Using a Transient Liquid Crystal 
Technique," AIAA Journal of Thermophysics and Heat Transfer, 14(2), 186-193.

https://doi.org/10.2514/2.6530

Biegger, C., Rao, Y., and Weigand, B., 2018, "Flow and Heat Transfer Measurements in Swirl Tubes with One and Multiple Tangential Inlet Jets for Internal Gas Turbine Blade Cooling," International Journal of Heat and Fluid Flow, 73, 174-187.

https://doi.org/10.1016/j.ijheatfluidflow.2018.07.011

Boyce, M.P., 2001, Gas Turbine Engineering Handbook, $2^{\text {nd }}$ ed., Gulf, USA.

Buttsworth, D.R. and Jones, T.V., 1997, "Radial Conduction Effects in Transient Heat Transfer Experiments," The Aeronautical Journal, 101(1005), 209-212.

Buzzard, W., Ren, Z., Ligrani, P., Nakamata, C., Ueguchi, S., 2016a, "Influences of Target Surface Roughness on Impingement Jet Array Heat Transfer: Part 1: Effects of Roughness Pattern, Roughness Height, and Reynolds Number," ASME Paper No. GT2016-56354, Proceedings of 2016 ASME International Gas Turbine Institute TurboExpo, Seoul, South Korea.

https://doi.org/10.1115/GT2016-56354

Buzzard, W., Ren, Z., Ligrani, P.M., Nakamata, C., Ueguchi, S., 2016b, "Influences of Target Surface Roughness on Impingement Jet Array Heat Transfer: Part 2: Effects of Roughness Shape, and Reynolds Number," ASME Paper No. GT2016-56355, Proceedings of 2016 ASME International Gas Turbine Institute TurboExpo, Seoul, South Korea. https://doi.org/10.1115/GT2016-56355

Carcasci, C., Tarchi, B.F.L., and Ohlendorf, N., 2014, "Experimental Investigation of a Leading Edge Cooling System with Optimized Inclined Racetrack Holes," ASME paper no. GT2014-26219, Proceedings of 2014 ASME International Gas Turbine Institute TurboExpo, Dusseldorf, Germany.

https://doi.org/10.1115/GT2014-26219

Chupp, R.E., Helms, D.E., McFadden, P.W., and Brown, T. R., 1969, "Evaluation of Internal Heat Transfer Coefficients for Impingement Cooled Turbine Airfoils" AIAA J. of Aircraft, 6(3), 203-208.

https://doi.org/10.2514/3.44036

Ekkad, S.V. and Han, J.C, 2000, "A transient liquid crystal thermography technique for gas turbine heat transfer measurements," Measurement Science and Technology, 11(7), 957-968.

https://doi.org/10.1088/0957-0233/11/7/312

Florschuetz, L.W., Berry, R.A., and Metzger, D.E., 1980, "Periodic Streamwise Variations of Heat Transfer Coefficients for Inline and Staggered Arrays of Circular Jets with Crossflow of Spent Air," ASME Journal of Heat Transfer, 102(1), 132-137.

https://doi.org/10.1115/1.3244224

Florschuetz, L.W., Truman, C.R., and Metzger, D.E., 1981, "Streamwise Flow and Heat Transfer Distributions for Jet Array Impingement with Crossflow," ASME Journal of Heat Transfer, 103(2), 337-342.

https://doi.org/10.1115/1.3244463

Gau, C. and Chung, C.M., 1991, "Surface Curvature Effect on Slot-AirJet Impingement Cooling Flow and Heat Transfer Process," ASME Journal of Heat Transfer, 113(4), 858-864.

https://doi.org/10.1115/1.2911214

Han, B. and Goldstein, R.J., 2001, "Jet-Impingement Heat Transfer in Gas Turbine Systems," Annals of New York Academy of Sciences, 934(1), 147-161.

https://doi.org/10.1111/j.1749-6632.2001.tb05849.x

Han, J.C., 2018, “Advanced Cooling in Gas Turbines 2016 Max Jakob Memorial Award Paper," ASME Journal of Heat Transfer, 140(11), 113001.

\section{https://doi.org/10.1115/1.4039644}

Han, J.C., Dutta, S., and Ekkad, S.V., 2012, Gas Turbine Heat Transfer and Cooling Technology, $2^{\text {nd }}$ ed., CRC Press, Boca Raton, FL.

Huang, Y., Ekkad, S.V., and Han, J.C., 1998, "Detailed Heat Transfer Distributions under an Array of Orthogonal Jets," AIAA Journal of Thermophysics and Heat Transfer, 12(1), 73-79.

https://doi.org/10.2514/2.6304

Huang, Y., Ekkad, S.V., and Han, J.C., 1998, "Detailed Heat Transfer Coefficient Distributions Under an Array of Inclined Impinging Jets Using a Transient Liquid Crystal Technique," 9th International Symposium on Transport Phenomenon in Thermal Fluids Engineering, ISTP-9, Singapore, June 25-28.

Jordan, C.N., Wright, L.M., and Crites, D.C., 2012, "Effect of Impingement Supply Condition on Leading Edge Heat Transfer with Rounded Impinging Jets," ASME Paper No. HT2012-58410, Proceedings of 2012 ASME Summer Heat Transfer Conference, Puerto Rico, USA.

https://doi.org/10.1115/HT2012-58410

Jordan, C.N., Elston, C.A., Wright, L.M., and Crites, D.C., 2013, "Leading Edge Impingement with Racetrack-shaped Jets and Varying Inlet Supply Conditions," ASME Paper No. GT2013-94611, Proceedings of 2013 ASME International Gas Turbine Institute TurboExpo, San Antonio, Texas. https://doi.org/10.1115/GT2013-94611

Jordan, C.N., Wright, L.M., and Crites, D.C., 2016, "Impingement Heat Transfer on a Cylindrical, Concave Surface with Varying Jet Geometries," ASME Journal of Heat Transfer, 138(12), 122202.

https://doi.org/10.1115/1.4034180

Kanokjaruvijit, K., and Martinez-Botas, R., 2005, "Parametric Effects on Heat Transfer of Impingement on Dimpled Surface," ASME Journal of Turbomachinery, 127(2), 287-296.

https://doi.org/10.1115/1.1791292

Kanokjaruvijit, K. and Martinez-Botas, R. F., 2008, "Heat Transfer and Pressure Investigation of Dimple Impingement," ASME Journal of Turbomachinery, 130(1), 011003.

https://doi.org/10.1115/1.2220048

Kercher, D.M., and Tabakoff, W., 1970, "Heat Transfer by a Square Array of Round Air Jets Impinging Perpendicular to a Flat Surface Including the Effect of Spent Air," ASME Journal of Engineering for Gas Turbines and Power, 92(1), 73-82. https://doi.org/10.1115/1.3445306

Kline, S.J. and McClintock, F.A., 1953, "Describing Uncertainty in Single Sample Experiments," Mechanical Engineering, 75, 3 - 8 .

Liu, Z. and Feng, Z.P., 2011, "Numerical simulation on the effect of jet nozzle position on impingement cooling of gas turbine blade leading edge," International Journal of Heat and Mass Transfer, 54(23-24), 4949-4959.

https://doi.org/10.1016/j.ijheatmasstransfer.2011.07.008

Metzger, D.E., Florschuetz, L.W., Takeuchi, D.I., Behee, R.D., and Berry, R.A., 1979, "Heat Transfer Characteristics for Inline and Staggered Arrays of Circular Jets with Crossflow of Spent Air," ASME Journal of Heat Transfer, 101(3), 526-531. https://doi.org/10.1115/1.3451022

Mhetras, S., Han, J.C., and Huth, M., 2013, "Impingement Heat Transfer from Jet Arrays on Turbulated Target Walls at Large Reynolds Numbers," ASME Paper No. GT2013-95893, Proceedings of 2013 ASME International Gas Turbine Institute TurboExpo, San Antonio, Texas. https://doi.org/10.1115/GT2013-95893 
Parbat, S.N., Siw, S.C., Chyu, M., 2016, "Impingement Cooling in Narrow Rectangular Channel With Novel Surface Features," ASME Paper No.GT2016-58084, Proceedings of 2016 ASME International Gas Turbine Institute TurboExpo, Seoul, South Korea. https://doi.org/10.1115/GT2016-58084

Taslim, M.E., Setayeshgar, L., and Spring, S.D., 2001a, "An Experimental Evaluation of Advanced Leading Edge Impingement Cooling Concepts," ASME Journal of Turbomachinery, 123(1), 147-153. https://doi.org/10.1115/1.1331537

Taslim, M.E. and Setayeshgar, L., 2001b, "Experimental Leading-Edge Impingement Cooling through Racetrack Crossover Holes," ASME Paper No. 2001-GT-0153, Proceedings of 2001 ASME International Gas Turbine Institute TurboExpo, New Orleans, Louisiana. https://doi.org/10.1115/2001-GT-0153

Taslim, M.E., Bakhtari, K., and Liu, H., 2003, "Experimental and Numerical Investigation of Impingement on a Rib-Roughened LeadingEdge Wall," ASME Journal of Turbomachinery, 125(4), 682-691. https://doi.org/10.1115/1.1624848

Taslim, M.E. and Khanicheh, A., 2005, "Experimental and Numerical Study of Impingement on an Airfoil Leading-Edge with and Without Showerhead and Gill Film Holes," ASME Journal of Turbomachinery, 128(2), 310-320.

https://doi.org/10.1115/1.2137742

Taslim, M.E. and Bethka, D., 2009, "Experimental and Numerical Impingement Heat Transfer in an Airfoil Leading-Edge Cooling Channel with Cross-Flow," ASME Journal of Turbomachinery, 131(1), 011021. https://doi.org/10.1115/1.2950058
Van Treuren, K.W., Wang, Z., Ireland, P. T., Jones, T. V., and Kohler, S. T., 1996, "Comparison and Prediction of Local and Average Heat Transfer Coefficients Under an Array of Inline and Staggered Impinging Jet," ASME Paper. No. 96-GT-163, Proceedings of 1996 ASME International Gas Turbine Institute TurboExpo, Birmingham, UK. https://doi.org/10.1115/96-GT-163

Wang, N., Chen A F., Zhang, M.J., and Han, J.C., 2018, "Turbine Blade Leading Edge Cooling with One Row of Normal or Tangential Impinging Jets," ASME Journal of Heat Transfer, 140(6), 062201. https://doi.org/10.1115/1.4038691

Weigand, B. and Spring, S., 2011, "Multiple Jet Impingement -A Review," Heat Transfer Research, 42(2), 101-142. https://doi.org/10.1615/HeatTransRes.v42.i2.30

Wright, L.M. and Han, J.C., 2014, "Heat Transfer Enhancement for Turbine Blade Internal Cooling," Journal of Enhanced Heat Transfer, 21(2-3), $111-140$.

https://doi.org/10.1615/JEnhHeatTransf.2015012169

Xing, Y., Spring, S., and Weigand, B., 2010, "Experimental and Numerical Investigation of Heat Transfer Characteristics of Inline and Staggered Arrays of Impinging Jets," ASME Journal of Heat Transfer, 132(9), 092201.

https://doi.org/10.1115/1.4001633

Yang, L., Ren, J., Jiang, H.D., and Ligrani, P.M., 2014, "Experimental and Numerical Investigation of Unsteady Impingement Cooling Within a Blade Leading Edge Passage", International Journal of Heat and Mass Transfer, 71(2014), 57-68. https://doi.org/10.1016/j.ijheatmasstransfer.2013.12.006 